\title{
Reactor design and selection for effective continuous manufacturing of pharmaceuticals
}

\author{
Chuntian $\mathrm{Hu}^{1}$ (D) \\ Received: 21 January 2021 / Accepted: 14 April 2021 / Published online: 18 May 2021 \\ (C) Akadémiai Kiadó 2021
}

\begin{abstract}
Pharmaceutical production remains one of the last industries that predominantly uses batch processes, which are inefficient and can cause drug shortages due to the long lead times or quality defects. Consequently, pharmaceutical companies are transitioning away from outdated batch lines, in large part motivated by the many advantages of continuous manufacturing (e.g., low cost, quality assurance, shortened lead time). As chemical reactions are fundamental to any drug production process, the selection of reactor and its design are critical to enhanced performance such as improved selectivity and yield. In this article, relevant theories, and models, as well as their required input data are summarized to assist the reader in these tasks, focusing on continuous reactions. Selected examples that describe the application of plug flow reactors (PFRs) and continuous-stirred tank reactors (CSTRs)-in-series within the pharmaceutical industry are provided. Process analytical technologies (PATs), which are important tools that provide real-time in-line continuous monitoring of reactions, are recommended to be considered during the reactor design process (e.g., port design for the PAT probe). Finally, other important points, such as density change caused by thermal expansion or solid precipitation, clogging/fouling, and scaling-up, are discussed.
\end{abstract}

Keywords Flow chemistry $\cdot$ Continuous manufacturing $\cdot$ PFR $\cdot$ CSTR $\cdot$ PAT $\cdot$ Residence time distribution

\section{Introduction}

Continuous manufacturing, or continuous processing, is defined as "the material(s) and product are continuously charged into and discharged from the system respectively, throughout the duration of the process" [1]. Industries such as food, petrochemicals and automotive, have long since adopted automated and continuous manufacturing, whereas pharmaceutical production remains one of the last industrial processes that mainly use a non-continuous (i.e., "batch") approach [2, 3]. This is because of the following differences that those other

\section{Article Highlights}

- The pharmaceutical industry is transitioning to continuous manufacturing due to its inherent advantages such as short lead time and quality assurance

- Theories for the design and selection of continuous reactors are summarized

- Selected examples of PFR and CSTRs-in-series applied in the pharmaceutical industry are discussed

Chuntian $\mathrm{Hu}$

chu@continuuspharma.com

1 CONTINUUS Pharmaceuticals, Woburn, MA 01801, USA industries did not have to consider: structural complexity, quality and regulatory, and quantity requirements (i.e., the trend towards lower dose drugs) [4]. This inefficient batch process can cause drug shortages due to the long lead times (up to 12 months) [2] or quality defects [1]. The current pharmaceutical industry operates at approximately 2-3 sigma quality ( $\sim 6.7-30.9 \%$ defects, i.e., failed / rejected products), thus, much improvement is required to achieve 6 sigma quality ( $\sim 0.0003 \%$ defects) [5]. Motivated by the benefits shown in Fig. 1 [6-10], the pharmaceutical industry is transitioning to continuous processes, including end-to-end integrated continuous manufacturing (ICM) approaches [1, 6, 8, 10-18]. A first-of-its-kind research demonstration of an end-to-end ICM line was unveiled by MIT in 2011 [13]. The model drug was aliskiren hemifumarate, and the throughput of the process was $45 \mathrm{~g} / \mathrm{h}$, with a residence time of $47 \mathrm{~h}$. Subsequently, the first commercial-setting end-to-end ICM pilot plant was reported by CONTINUUS Pharmaceuticals in 2019 [12]. The throughput of the process was 4800 tablets per hour, or $40.3 \times$ $10^{6}$ tablets per year, with a total residence time of $<30 \mathrm{~h}$. There are examples of continuously manufactured drug products that have been approved in the US (e.g., Orkambi, Symdeko and Trikafta by Vertex, Prezista by Johnson \& Johnson, Verzenio 


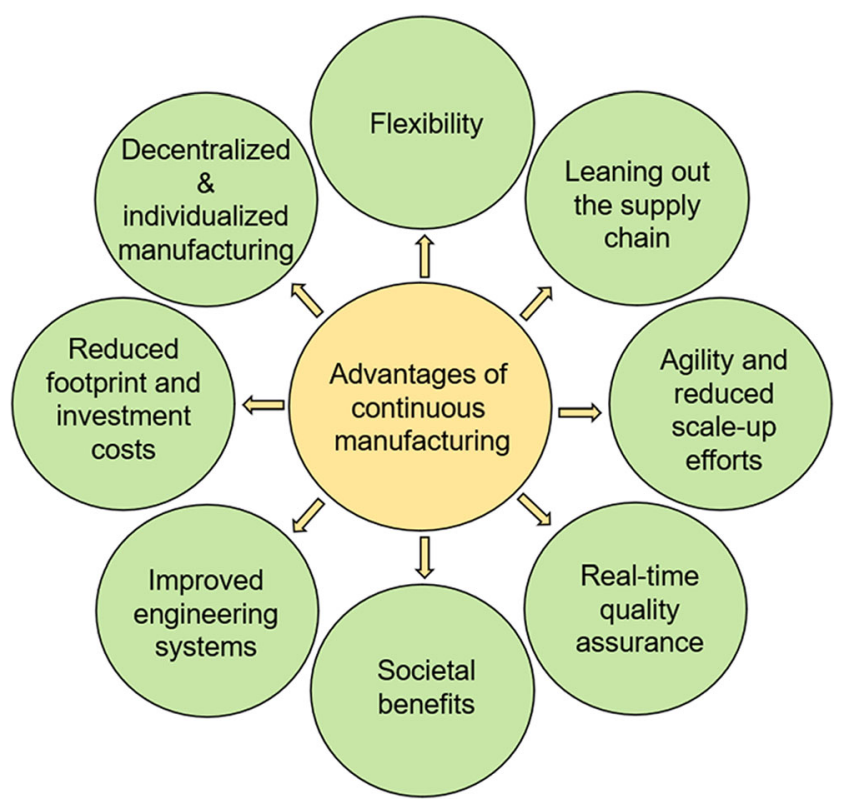

Fig. 1 Benefits of continuous manufacturing

by Eli Lilly, Daurismo by Pfizer), in the EU (e.g., Orkambi and Symkevi by Vertex, Prezista by Johnson \& Johnson, Verzenios by Eli Lilly), and in Japan (e.g., Tramacet by Johnson \& Johnson, Verzenio by Eli Lilly), as well as drugs that are under development $[12,16,19]$.

The reaction is one of the necessary steps in the continuous manufacturing of pharmaceuticals. There are many types of reactions (e.g., imidazole cyclization, hydroformylation, reductive amination, thermal deprotection) that could be performed in continuous reactors. In addition, some can occur simultaneously with crystallization (i.e., reactive crystallization), when the solubility of the active pharmaceutical ingredient (API) is low but the reaction rate is high. Thus, appropriate reactor design and selection for different reactions are essential to ensure desirable performance of the manufacturing process (e.g., high selectivity and yield). There are three main categories of ideal reactors: batch reactors, plug flow reactors (PFR, also known as tubular reactors), and continuous-stirred tank reactors (CSTRs, also known as backmixing reactors) $[20,21]$; the last two are continuous. In batch reactions, raw materials and solvents are charged into the reactor at the beginning, and the product is collectively discharged at the end [1]. The composition within the batch reactor changes with time, the residence time is uniform, and there is no flow through the process. These reactors are usually used for small-scale production and for testing new processes, especially those with complex chemistry.

In continuous reactions, raw materials and solvents are continuously charged into the system, and the product is continuously discharged from the system throughout the duration of the process [1]. An ideal PFR has no axial mixing, but perfect radial mixing. In a PFR, all materials passing through experience the same concentration and temperature profiles along its length and have the same residence time. Conversely in a CSTR, although all the materials have uniform temperature, pressure, and concentration, the residence time is characterized by a distribution (residence time distribution, RTD). This is because some components that enter the reactor can leave immediately, while others remain for longer time periods. Usually one CSTR cannot achieve complete conversion, and CSTRs-in-series are used to approximate a PFR. PFRs and CSTRs-in-series are popular continuous reactors that are widely used in the pharmaceutical industry. Figure 2 and Table 1 compare the differences between a PFR and CSTRs-in-series [24-26]. This article summarizes theories for the design and selection of continuous reactors, and highlights some examples of PFRs and CSTRs-in-series within the pharmaceutical industry.

\section{Selected data collection}

The design and selection of a continuous reactor depends on many parameters including reaction kinetics, enthalpy of reaction, heat and mass transfer, etc. A more effective design can be made when a large amount of input data is available; however, this is not always the case. Reaction kinetics and enthalpy of reaction are parameters of paramount interest, since they dictate the amount of reaction time needed, reaction conditions (e.g., pressure, temperature, catalyst) and the heating management of the reactor, respectively.

\section{Reaction kinetics}

Reaction kinetics is the study of the reaction rate and mechanism by which the reactants are transformed into products [27]. In most cases the reaction rate constants and rate equations need be approximated, as they cannot be predicted from first principles [28]. Accordingly, the main process reactions are usually approximated as first-order or second -order, and over a narrow range of conditions (e.g., concentration, temperature, pressure) [29]. The reactor design and selection discussed in this article is based on non-zero-order reactions.

For a first-order reaction (i.e., a reaction that proceeds at a rate that depends linearly on the concentration of one reactant $[20,21])$,

\section{$A($ reactant $) \rightarrow P($ product $)$}

The reaction rate equation for this first-order reaction is [20, 21].

$r=-\frac{d c_{A}}{d t}=\frac{d c_{P}}{d t}=k_{1} C_{A}$ 
Table 1 Comparison of a PFR and CSTRs-in-series for selected aspects

\begin{tabular}{|c|c|c|}
\hline Aspect & PFR & CSTRs-in-series \\
\hline Headspace & No, and $100 \%$ liquid fill is achievable & $\begin{array}{l}\text { Yes, and it is feasible to adjust the residence } \\
\text { time without changing the flow rate }\end{array}$ \\
\hline Minimum working volume & On the order of $\mu \mathrm{L}$ & On the order of $\mathrm{mL}$ or higher \\
\hline Minimum residence time & On the order of seconds or below & On the order of $10 \mathrm{~s}$ \\
\hline RTD & Narrow & $\begin{array}{l}\text { Broad, and will be narrower after integration } \\
\text { of more CSTRs }\end{array}$ \\
\hline Mixing & $\begin{array}{l}\text { No axial mixing for ideal reactors; mixing depends on flow rate for real } \\
\text { reactors }\end{array}$ & $\begin{array}{l}\text { Perfect mixing for ideal reactors; mixing is } \\
\text { independent of flow rate }\end{array}$ \\
\hline Solid handling capability & Low, and easily clog & Higher robustness to clogging \\
\hline Heat transfer & Excellent & $\begin{array}{l}\text { Good, and better than a batch reactor for the } \\
\text { same throughput }\end{array}$ \\
\hline Temperature limit & $\begin{array}{l}\text { Wide temperature range, including extreme temperatures, e.g., }-80 \sim \\
300{ }^{\circ} \mathrm{C}[22]\end{array}$ & Typically $-30 \sim 150{ }^{\circ} \mathrm{C}$ \\
\hline Pressure limit & Could carry out very high pressure reactions, e.g., 70 bar [23] & Usually mild pressure \\
\hline Feed Stoichiometry & $\begin{array}{l}\text { Critical; if stoichiometry oscillates, a small CSTR before the PFR could } \\
\text { help to dampen out fluctuations [24] }\end{array}$ & $\begin{array}{l}\text { Not very critical, and CSTR could buffer out } \\
\text { the fluctuations in stoichiometry }\end{array}$ \\
\hline Concentration & Constant for a given location; decrease along the length & $\begin{array}{l}\text { Constant for a given CSTR; decrease stage by } \\
\text { stage }\end{array}$ \\
\hline Single/multiphase reactions & $\begin{array}{l}\text { Gas-, liquid-, gas-liquid, and liquid-liquid phases reactions, and some } \\
\text { solid-related reactions (e.g., hydroformylation reaction [25]) }\end{array}$ & Liquid-, liquid-liquid, and liquid-solid phases \\
\hline Cost & Low & Higher than PFR \\
\hline
\end{tabular}

Here $r$ is reaction rate, and $C_{A}$ and $C_{P}$ are the reactant and product concentrations, respectively. $k_{1}$ is the rate constant for first-order reaction. Integrating eq. (1), we obtain eq. (2),

$k_{1}=\frac{1}{t} \ln \frac{C_{A 0}}{C_{A}}$

$C_{A 0}$ is the original reactant concentration, and the unit for $k_{1}$ is time $^{-1}$.

For a second-order reaction, the sum of the exponents in the rate law is equal to two.

$A($ reactant $)+B($ reactant $) \rightarrow P($ product $)$

The reaction rate equation for this second-order reaction is $[20,21]$.

$r=-\frac{d c_{A}}{d t}=-\frac{d c_{B}}{d t}=\frac{\mathrm{d} c_{P}}{d t}=k_{2} C_{A} C_{B}$

Here $C_{B}$ is the concentration of reactant $\mathrm{B}$, and $k_{2}$ is the rate constant for second-order reaction. Integrating eq. (3), we obtain eqs. (4) and (5),

$$
\begin{aligned}
& k_{2}=\frac{1}{t}\left(\frac{1}{C_{A}}-\frac{1}{C_{A 0}}\right),\left(\text { if } C_{A 0}=C_{B 0}\right) \\
& k_{2}=\frac{1}{t\left(C_{A 0}-C_{B 0}\right)} \ln \frac{C_{B 0} C_{A}}{C_{A 0} C_{B}},\left(\text { if } C_{A 0} \neq C_{B 0}\right)
\end{aligned}
$$

$C_{B 0}$ is the original concentration of reactant $\mathrm{B}$, and the unit of $k_{2}$ is (concentration) ${ }^{-1} \cdot$ (time $^{-1}$.

The Arrhenius equation is an expression for the temperature dependence of reaction rates (eq. (6)) [20, 21].

$k=A \exp \left(-\frac{E}{R T}\right)$

where $k$ is the rate constant at temperature T, $R$ is the molar gas constant, $A$ is the pre-exponential factor, and $E$ is the apparent activation energy.

\section{Enthalpy of reaction}

Enthalpy of a reaction, $\Delta H_{r}$, is defined as the heat energy change that takes place when reactants convert into products. If the sum of the enthalpies of the products is greater than that of the reactants, the reaction will be endothermic. Conversely, if the reactants have larger enthalpies, the reaction will be exothermic.

Under standard condition (i.e., temperature of $25^{\circ} \mathrm{C}$ and pressure of $1 \mathrm{~atm}$ ), the standard enthalpy of reaction, $\Delta H_{r}^{\varnothing}$, is calculated below,

$\Delta H_{r}^{\varnothing}=\Delta H_{f}^{\varnothing}($ products $)-\Delta H_{f}^{\varnothing}($ reactants $)$

where $\Delta H_{f}^{\varnothing}$ is the standard enthalpy of formation (i.e., the enthalpy change during the formation of $1 \mathrm{~mol}$ of 
Fig. 2 Reactor schematics, reactant concentration profiles and design equations for (a) PFRs, and (b) CSTRs-in-series
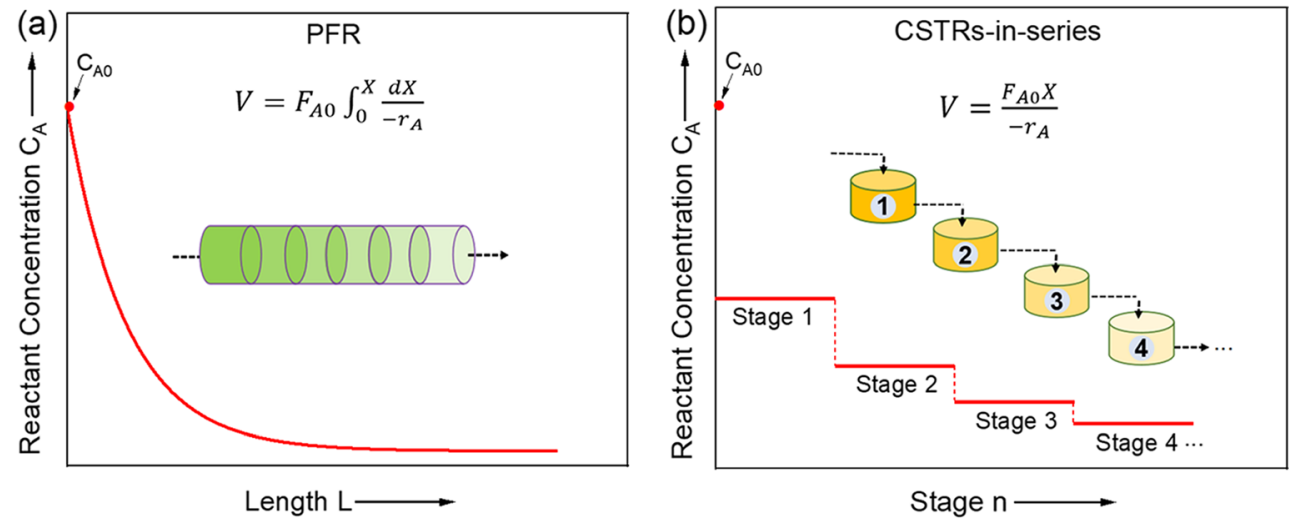

the substance from its constituent elements under standard state).

Under process conditions of temperature $T$ and pressure $P$, the enthalpy of reaction $\left(\Delta H_{r, P, T}\right)$ is expressed as eq. (8) [29].

$$
\begin{aligned}
\Delta H_{r, P, T}^{\varnothing}= & \Delta H_{r}^{\varnothing}+\int_{1}^{P}\left[\left(\frac{\partial H_{\text {prod. }}}{\partial P}\right)_{T}-\left(\frac{\partial H_{\text {react. }}}{\partial P}\right)_{T}\right] d P \\
& +\int_{298.15}^{T}\left[\left(\frac{\partial H_{\text {prod. }}}{\partial T}\right)_{P}-\left(\frac{\partial H_{\text {react. }}}{\partial T}\right)_{P}\right] d T
\end{aligned}
$$

If temperature is the only parameter that needs to be accounted for, the equation is simplified [29],

$\Delta H_{r, T}^{\varnothing}=\Delta H_{r}^{\varnothing}+\Delta H_{\text {prod. }}+\Delta H_{\text {react } .}$

where $\Delta H_{\text {prod. }}$ and $\Delta H_{\text {react. }}$ are the enthalpy change of the products and reactants, respectively, when their temperature changes from $298.15 \mathrm{~K}$ to $\mathrm{T}$.

Other parameters, such as equilibrium constant and Gibbs free energy, are also useful for reactor design. The heat and mass transfer properties are especially important for multiphase reactors. These parameters will not be discussed here.

\section{RTD theory, dispersion model and CSTRs-in-series model}

\section{RTD theory}

Residence time describes the length of time that a molecule or reaction material spends in a reactor. It is an important characteristic of any reactor. Material in an ideal batch reactor or an ideal PFR has a single residence time. However, for all other reactor types, multiple residence times exist, and they are expressed as a function of time by the residence time distribution (RTD) [20, 21, 30].

For the pulse injection of the tracer, the mean residence time, $\bar{t}$, and variance, $\sigma^{2}$, can be obtained by $[20,21]$. $\bar{t}=\frac{\int_{0}^{\infty} t C(t) d t}{\int_{0}^{\infty} C(t) d t}$

and

$\sigma^{2}=\frac{\int_{0}^{\infty} t^{2} C(t) d t}{\int_{0}^{\infty} C(t) d t}-\bar{t}^{2}$

The RTD function of $E(t)$ is calculated from the pulse tracer experiments by $[20,21]$.

$E(t)=\frac{C(t)}{\int_{0}^{\infty} C(t) d t}$

The dimensionless function, $E(\theta)$, which offers a direct comparison of experimental results for different conditions (e.g., different flowrates, different reactor sizes), is calculated by $[20,21]$.

$E(\theta)=\frac{C(\theta)}{\int_{0}^{\infty} C(\theta) d \theta}$

where the dimensionless time, $\theta$, is calculated from the ratio of the real time, $\mathrm{t}$, to the mean residence time, $\bar{t},[20,21]$.

$\theta=\frac{t}{\bar{t}}$

\section{Axial dispersion model}

The axial dispersion model is usually used to describe non-ideal PFRs. The vessel dispersion number, $D^{*} / u L$, is the parameter that determines axial dispersion. When $D^{*} / u L<0.01$, the system emulates plug flow, and $E(\theta)$ is expressed as [21].

$E(\theta)=\frac{1}{\sqrt{4 \pi\left(D^{*} / u L\right)}} \exp \left[-\frac{(1-\theta)^{2}}{4\left(D^{*} / u L\right)}\right]$ 
where $u$ is the fluid velocity, $L$ is the reactor length, and $D^{*}$ is the axial dispersion coefficient, which is defined by [21].

$D^{*}=\mathcal{D}+\frac{u^{2} d_{t}^{2}}{192 \mathcal{D}}$

where $\mathcal{D}$ is the diffusion coefficient and $d_{t}$ is the tube diameter. The variance, $\sigma_{\theta}^{2}$, is calculated by [21].

$\sigma_{\theta}^{2}=\frac{2 D^{*}}{u L}$

Accordingly, when $D^{*} / u L>0.01$, the system is open and far from plug flow, and $E(\theta)$ and its variance are expressed as [21].

$E(\theta)=\frac{1}{\sqrt{4 \pi\left(D^{*} / u L\right) \theta}} \exp \left[-\frac{(1-\theta)^{2}}{4 \theta\left(D^{*} / u L\right)}\right]$

and

$\sigma_{\theta}^{2}=\frac{2 D^{*}}{u L}+8\left(\frac{D^{*}}{u L}\right)^{2}$

The axial dispersion coefficient $D^{*}$ can be estimated from the maximum peak heights of either $E(\theta)$ curves.

\section{CSTRs-in-series model}

The CSTRs-in-series model can be used when there is less deviation from plug flow. This model is simple, can be used with any kinetics, and can be extended to any arrangement of compartments (with or without recycle) [21].

For the $n$th CSTR, the RTD function of $E(t)$ and its variance are expressed as [21,31].

$E(t)=\frac{t^{n-1}}{\bar{t}^{n}} \frac{n^{n}}{(n-1) !} e^{-t n / t}$

and

$\sigma^{2}=\frac{\bar{t}^{2}}{n}$

The dimensionless function $E(\theta)$ and its variance are expressed as [21,31].

$E(\theta)=n \frac{(n \theta)^{n-1}}{(n-1) !} e^{-n \theta}$

and

$\sigma_{\theta}^{2}=\frac{1}{n}$

\section{PFR}

Ideal PFRs and batch reactors are characterized by a single uniform residence time. For non-ideal reactors, a PFR's RTD is broader than that of a batch reactor, but narrower than that of a CSTR. In the production of APIs, batch reactors and PFRs have been widely used, and complete conversion is achievable [30]. For some reactions such as organic azide or tetrazole formations, a PFR is preferable because it operates $100 \%$ liquid filled, while a batch reactor or CSTR typically has a headspace where hydrazoic acid would partition [24, 32]. Compared with CSTRs-in-series, PFR is usually lower in cost (e.g., less materials required for research and development, and a PFR is cheaper than CSTRs-in-series) and in complexity. To manufacture the APIs continuously, a PFR is preferred, unless it is not practical (e.g., clogging issues). PFRs can be used for gas-, liquid-, gas-liquid, and liquid-liquid phases reactions, and some solid-related reactions (e.g., hydroformylation reaction [23]), although it is challenging to handle solids.

In a PFR, we assumed that the concentration varies continuously in the axial direction along the reactor length, but no change with time for a given location [20,24]. The required volume $(V)$ to achieve the specified conversion $X$ is [20],

$V=F_{A 0} \int_{0}^{X} \frac{d X}{-r_{A}}$

where $F_{A 0}$ is the molar flowrate of reactant $\mathrm{A}$, and $-r_{A}$ is the reaction rate of reactant A. Under experimental conditions, PFRs are not ideal because of the axial dispersion (Fig. 3). In pharmaceutical applications, the flow is usually laminar (i.e., $\operatorname{Re}<2300$ ) because of the low throughput and small characteristic dimension. Turbulent flow is achieved when $\operatorname{Re}>4000$.

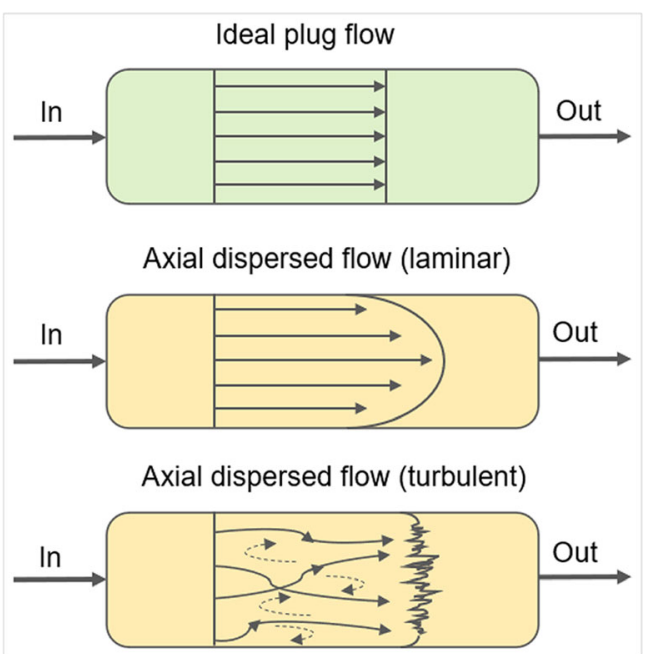

Fig. 3 Comparison of ideal plug flow and axial dispersed plug flow 
The general form of correlation for $D^{*} / u L$ is described by equation $[33,34]$,

$\frac{D^{*}}{u L}=($ intensity of dispersion $)$ (geometric factor $)$

where intensity of dispersion is defined as $D^{*} / u d_{t}$, which correlates to Reynolds number, $R e$, and Schmidt number, $S c$, [21].

$R e=\frac{\rho u d_{t}}{\mu}$

$S c=\frac{\mu}{\rho \mathcal{D}}$

Where $\rho$ is the density, and $\mu$ is the dynamic viscosity. For straight tubing, the geometric factor is $d_{t} / L$ (i.e., the reverse of the common used form $L / d_{t}$ ). Typically, higher $L / d_{t}$ leads to lower $D^{*} / u L$. It is interesting to note that for smaller tubes, there was less axial dispersion at lower flow rates, but for larger tubes, there was more axial dispersion at lower flow rates [33]. For coiled tubes, the geometric factor is more complex, and the coil diameter $d_{c}$ matters. As reported, under certain assumptions the logarithm of $D^{*}$ decreased linearly with the logarithm of the dimensionless parameter $D e^{2} S c^{1.14}$ [35], where $D e$ is the Dean number [36], a key parameter for coiled flows, [21].

$D e=\left(\frac{d_{t}}{d_{c}}\right)^{\frac{1}{2}} R e$

When coil diameter decrease, $D e$ and $D e^{2} S c^{1.14}$ will increase. Therefore, the axial dispersion reduced.

Furthermore, it is helpful for better understanding of the reaction system if we can estimate the conversion along the length of the PFR. The conversion is mainly influenced by residence time, reaction order, reaction rate and axial dispersion. Consider a PFR with length $L$, within which chemicals are mixing axially with a dispersion number of $D^{*}$. For a $n$ th-order reaction with reactant $\mathrm{A}$, the reaction conversion in this nonideal PFR can be estimated with simulation software (e.g., MATLAB) by the following equation [21, 37],

Table 2 Comparison of the experimental and simulated conversion results in a PFR (Adapted from Ref. [16] with permission from the Royal Society of Chemistry)

\begin{tabular}{lllllc}
\hline$\#$ & $\begin{array}{l}\text { Temperature } \\
\left({ }^{\circ} \mathrm{C}\right)\end{array}$ & $\begin{array}{l}\text { Experimental } \\
\mathrm{X}(\%) *\end{array}$ & $\begin{array}{l}\text { Simulated } \\
\mathrm{X}(\%)\end{array}$ & Error & Error\% \\
\hline 1 & $\mathrm{~T}-5$ & 31.8 & 25.1 & -6.7 & -21.1 \\
2 & $\mathrm{~T}$ & 36.2 & 32.2 & -4.0 & -11.3 \\
3 & $\mathrm{~T}+5$ & 40.6 & 39.7 & -0.9 & -2.22 \\
\hline
\end{tabular}

$\frac{D^{*}}{u L} \frac{d^{2} X}{d z^{2}}-\frac{d X}{d z}+k \tau C_{A 0}^{n-1}(1-X)^{n}=0$

where $\mathrm{z}=l / L$, and $l$ is the length from the entrance. At the exit, $l=L$. From this equation, we observe that the fraction conversion of reactant A through the PFR is controlled by $D^{*} / u L$ and $\tau k C_{A 0}^{n-1}$ [21]. From Fig. 4a, if a first-order reaction requires $90 \mathrm{~min}$ to reach $99.9 \%$ conversion in an ideal PFR (i.e., $D^{*} / u L=0$ ), the mean residence time for $D^{*} / u L$ of $0.002,0.025$ and 0.2 are 91.2, 105 and $196 \mathrm{~min}$, respectively (assuming the same reaction conditions) [33]. Figure $4 \mathrm{~b}$ and Table 2 provide an example of the simulated conversion results as a function of $\mathrm{z}$ for three different temperatures for a second-order reaction.

It is important to note that the conversion profile will not be as smooth as shown in Fig. 4, especially when there exists a "hot spot" (i.e., an area or point within a reaction system at which the temperature is appreciably higher than in the bulk of the reactor), for exothermic reactions. The existence of a "hot spot" depends mainly on a reactor's specific area (i.e., surface area per reactor volume). Specific areas greater than $10^{4} \mathrm{~m}^{2} /$ $\mathrm{m}^{3}$ can only be achieved in microreactors. Usually the specific area in a PFR is less than $2000 \mathrm{~m}^{2} / \mathrm{m}^{3}$. Scaling up the inner diameter (i.d.) from $2 \mathrm{~mm}$ to $10 \mathrm{~mm}$, decreases the specific area from 2000 to $400 \mathrm{~m}^{2} / \mathrm{m}^{3}$ (Table 3).

Although it is not feasible to measure the temperature at all points along the length of a PFR, numerical modeling is an alternative method to estimate the temperature profile throughout the PFR. Fogler [20] derived the energy balance for a non-isothermal PFR, as expressed in eq. (30), which provides the temperature profile along the length of the PFR.

$\frac{d T}{d V}=\frac{r_{A}(T) \Delta H_{r x n}(T)-U a\left(T-T_{a}\right)}{\sum F_{i} C_{P_{i}}}$

Where $\frac{d T}{d V}$ is the temperature change of the process fluids in a segment of the reactor, $\Delta H_{r x n}(T)$ is the heat of reaction at temperature $\mathrm{T}, r_{A}(T)$ is the reaction rate of species A at temperature T, $U$ is the overall heat-transfer coefficient, $a$ is the PFR heat-exchange area per volume of reactor, $T$ is the temperature of the process fluids, $T_{a}$ is the temperature of the heating or cooling media, $F_{i}$ is the mole flow rate of species $i$, and $C_{P_{i}}$ is the mean heat capacity of species $i$. Based on eq. (30), Johnson et al. [25] reported a steady-state temperature profile along a PFR for a homogeneous cryogenic lithiation reaction. The simulation result showed the existence of a hot spot, although it is not physically measurable.

Figure 5 and Table 4 provide examples of typical PFR reactors and reactions performed in a PFR. Cole et al. [42] reported kilogram-scale prexasertib monolactate monohydrate synthesis under continuous-flow cGMP conditions, which included a seven-step route. Three of these steps used a PFR. 


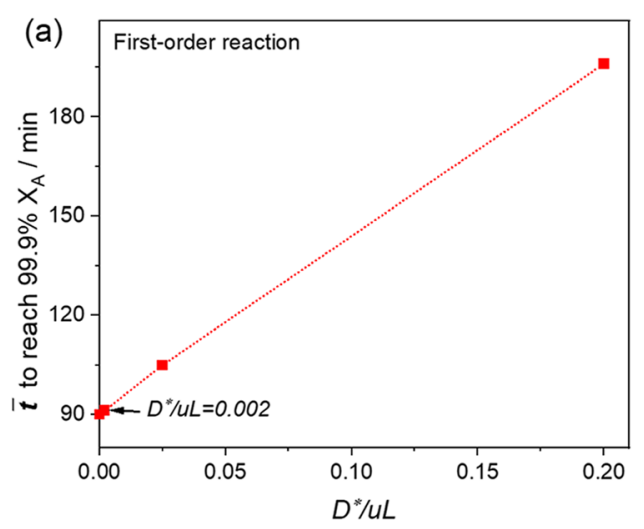

Fig. 4 (a) Influence of axial dispersion on $\bar{t}$ for a first-order reaction that requires 90 min to reach conversion of $99.9 \%$ in an ideal PFR (Fig. 4a is reproduced with permission from Ref. [33] Table 6. Copyright 2012 American Chemical Society), and (b) simulated conversion results as a

The first PFR was used to optimize a hydrazine condensation reaction in flow (step 1 in Table 4a). For reference, in batch mode, a large molar excess of hazardous hydrazine is required, and the transformation proceeds slowly. Conversely, in flow mode, stainless steel (SS) tubing with inner diameter (i.d.) of $4.57 \mathrm{~mm}$, length of $91 \mathrm{~m}$, and volume of $1.4 \mathrm{~L}$ was used. The throughput was $3.4 \mathrm{~kg} / \mathrm{day}$, the residence time was $60 \mathrm{~min}$, and the reaction was operated under $130{ }^{\circ} \mathrm{C}$ and 34.5 bar, conditions not feasible with batch reactors. Minor impurities were observed at the end of the reaction. The second PFR was used for a nucleophilic aromatic substitution reaction coupling a pyrazole and pyrazine (step 2 in Table 4a). The flow reaction was conducted in low pressure PFA tubing with inner diameter (i.d.) of $6.35 \mathrm{~mm}$, length of $91 \mathrm{~m}$, and volume of $2.8 \mathrm{~L}$. The liquid flowed from the bottom to the top of the horizontally coiled tube (immersed in a heated bath) to ensure liquid filled. The throughput was $2.9 \mathrm{~kg} /$ day of the pyrazole product, the residence time was $180 \mathrm{~min}$, and the reaction temperature and pressure were $70^{\circ} \mathrm{C}$, and atmospheric pressure, respectively. The third PFR was used for deprotection with simultaneous gas and liquid handling (step 3 in Table 4a). This reaction exhibited excellent robustness between 20 and $40{ }^{\circ} \mathrm{C}$, with a residence time between 2 and $6 \mathrm{~h}$. The PFA coiled tubing (15.9 $\mathrm{mm}$ i.d.) was vertically oriented, and operated $50 \%$ filled with liquid and $50 \%$ filled with $\mathrm{N}_{2}$ carrier gas. Less impurities were produced when the

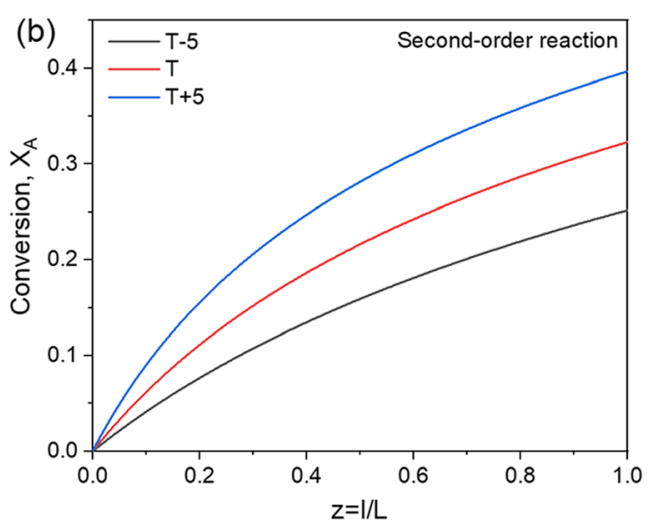

function of $\mathrm{z}$ for three different temperatures for a second order reaction. (Fig. 4b is adapted from Ref. [16] with permission from the Royal Society of Chemistry)

generated $\mathrm{CO}_{2}$ and iso-butylene were removed in situ. The characterization of this PFR revealed plug flow operation with a $D^{*} / u L$ of 0.003 , which approximates the RTD of 140 equalvolume CSTRs-in-series.

Mascia and Patrick et al. [13, 43] developed a multi-step synthesis and workup sequence for aliskiren hemifumarate, and PFRs were used in two steps (Table 4b). A melted chemical intermediate was pumped into the first PFR (i.d. of $11.7 \mathrm{~mm}$, length of $25 \mathrm{~m}$, volume of $2.7 \mathrm{~L}$ ) at $100{ }^{\circ} \mathrm{C}$, where it was mixed with 10 equiv. amine and 1 equiv. acid catalyst. This single-phase reaction was much faster when run neat, compared to the batch reaction (3-4 h vs. $72 \mathrm{~h}$ ). The diffusion coefficient was $1 \times 10^{-9} \mathrm{~m}^{2} / \mathrm{s}$ when the nominal flow rate of $675 \mathrm{~mL} / \mathrm{h}$ was used. The second PFR (i.d. of $4 \mathrm{~mm}$, length of $4.9 \mathrm{~m}$, volume of $0.062 \mathrm{~L}$ ) was used for the acid-catalyzed removal of the Boc protecting group. The reaction formed $\mathrm{CO}_{2}$ gas that created irregular flow patterns within the $4 \mathrm{~mm}$ i.d. tubing. It was observed that orientating the reactor coil horizontally resulted in 1-2\% higher yield, with a peak yield being obtained at $30^{\circ} \mathrm{C}$ [43].

Johnson and May et al. [25, 33] investigated imidazole cyclization (Table 4c) for GMP production of $29 \mathrm{~kg}$ of an advanced intermediate. They utilized a $7.1 \mathrm{~L}$ coiled stainless steel tube thermal PFR (151 m long, $7.75 \mathrm{~mm}$ i.d.) with a specific area of $516 \mathrm{~m}^{2} / \mathrm{m}^{3}$, and concluded that this specific area was sufficient to achieve adequate heat-up and cool-
Table 3 A comparison of the specific area for typical reactors

\begin{tabular}{lcl}
\hline Reactor type & $\begin{array}{l}\text { Length/Diameter ratio } \\
\left(\mathrm{L} / \mathrm{d}_{\mathrm{t}}\right)\end{array}$ & $\begin{array}{l}\text { Specific area } \\
\left(\mathrm{m}^{2} / \mathrm{m}^{3}\right)\end{array}$ \\
\hline $10 \mathrm{~L}$ batch reactor & - & $\sim 20$ \\
$1 \mathrm{~L}$ batch reactor & - & $\sim 50$ \\
$1 \mathrm{~L}$ PFR with inner diameter of $10 \mathrm{~mm}$ & $1.3 \times 10^{3}$ & 400 \\
$1 \mathrm{~L}$ PFR with inner diameter of $2 \mathrm{~mm}$ & $1.6 \times 10^{5}$ & 2000 \\
$140 \mu \mathrm{L}$ microreactor with channel of $400 \times 400 \mu \mathrm{m}[38]$ & $2.0 \times 10^{4}$ & $10^{4}$ \\
\hline
\end{tabular}


Table 4 Selected examples of reactions performed in a PFR.

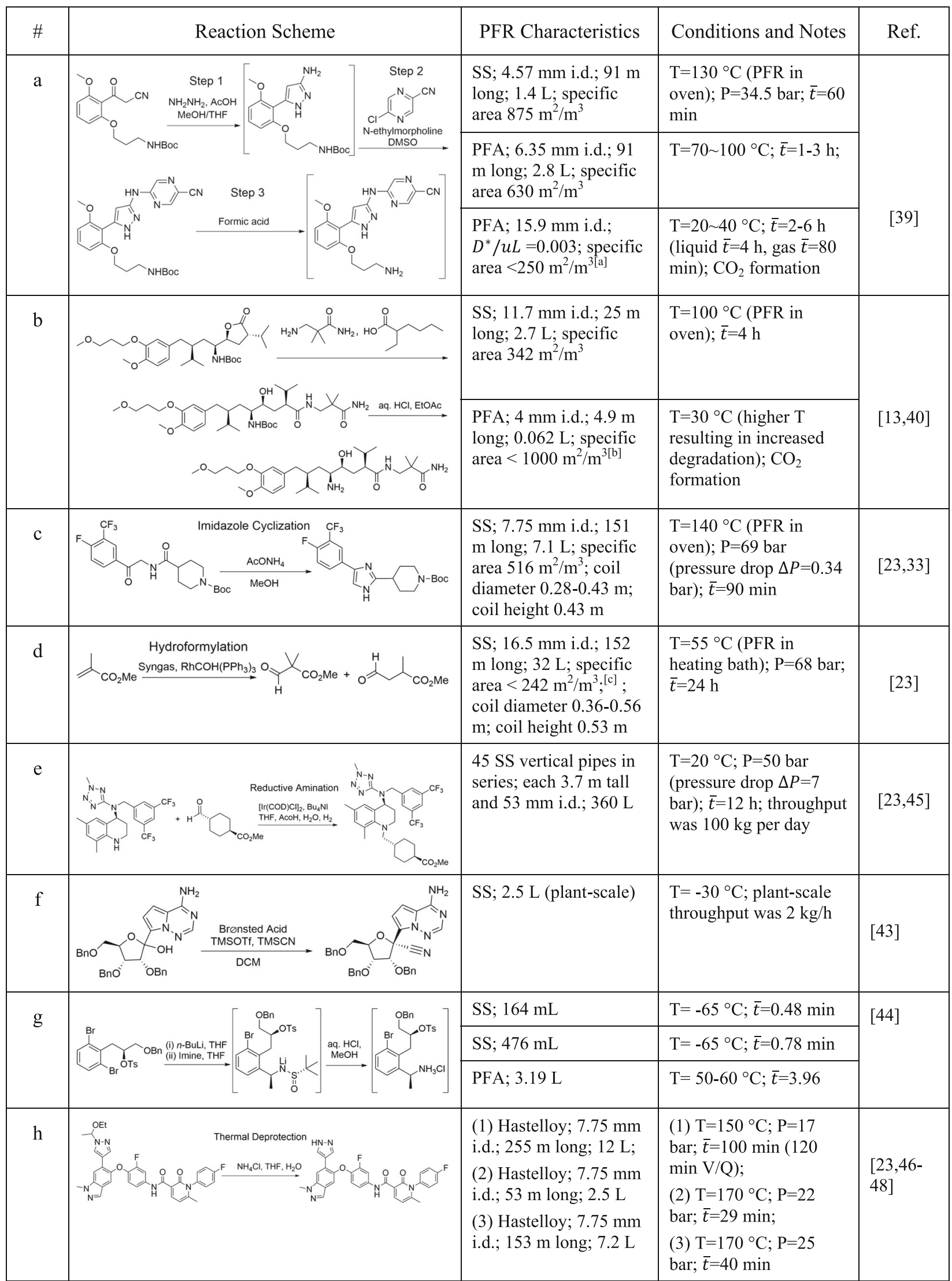

[a] The tubing was operated 50\% filled with liquid and 50\% with $\mathrm{N}_{2}$ gas; $\mathrm{CO}_{2}$ gas was formed in the reaction; [b] the real specific area should be less than $1000 \mathrm{~m}^{2} / \mathrm{m}^{3}$ as $\mathrm{CO}_{2}$ gas was formed in the reaction; [c] vapor and liquid mixture; 
down times [25]. The reaction was carried out under extreme conditions (i.e., $140{ }^{\circ} \mathrm{C}, 69$ bar), which exceed typical limitations of batch reactors. However, these conditions are feasible with SS PFRs without any scale-up issues. Under these reaction conditions, the pressure drop $(\Delta P)$ from inlet to outlet is about 0.34 bar. Pressure drop along the length of the PFR can be estimated by the Hagen-Poiseuille equation [33, 48],

$\Delta P=\frac{8 \mu L Q}{\pi R^{4}}=\frac{8 \pi \mu L Q}{A^{2}}$

where $Q$ is the volumetric flow rate, $R$ is the pipe radius, and $A$ is the cross section of the pipe.

The scheme in Table $4 \mathrm{~d}$ shows a hydroformylation reaction [23], where solid precipitated from the reaction mixture. A $32 \mathrm{~L}$ SS pulsating coiled tube reactor (with $16.5 \mathrm{~mm}$ i.d., $152 \mathrm{~m}$ length, see Fig. 5a-b) was operated under 68 bar and $55^{\circ} \mathrm{C}$. The syngas was composed of $1: 1 \mathrm{CO}$ and $\mathrm{H}_{2}$, and the substrate to $\mathrm{RhCOH}\left[\mathrm{PPh}_{3}\right]_{3}$ catalyst ratio was 1000 . It was not practical to increase the catalyst loading because: 1 ) the cost of $\mathrm{Rh}$ is high, and 2) the catalyst could precipitate from the reaction mixture, causing clogging and fouling issues. The reactor had pulsating flows in the forward and backward direction to prevent clogging. The residence time was $24 \mathrm{~h}$, and decreasing the reaction time by increasing the temperature was not practical, as more linear aldehyde (undesired product) was generated at higher temperatures.
May et al. [44] investigated the GMP scale-up of a continuous Ir-catalyzed homogeneous reductive amination reaction (two phase gas-liquid reaction) between a secondary amine and a trans-aldehyde to produce a tertiary amine (Table 4e). A vertical pipes-in-series bubble flow reactor was constructed from $45 \mathrm{SS}$ pipes $\left(3.7 \mathrm{~m}\right.$ tall, $53 \mathrm{~mm}$ i.d., $\left.D^{*} / u L=0.001\right)$, connected by $4.6 \mathrm{~mm}$ i.d. down-jumper tubes (Fig. $5 \mathrm{c}$ ) [25, 44]. The reaction was operated under $20^{\circ} \mathrm{C}, 50$ bar, a $12 \mathrm{~h}$ residence time, and with dissolved $[\operatorname{Ir}(\mathrm{Cod}) \mathrm{Cl}]_{2}$ catalyst. The throughput was $100 \mathrm{~kg} /$ day and the plant was run continuously for 24 days. Compared with the batch process, this continuous reactor was safer because: 1) the amount of $\mathrm{H}_{2}$ vapor space was low ( $\sim 2 \%$ of the reactor volume), and 2 ) the reactor was located outside of the building, which was not feasible for batch reactors that required frequent reagent and catalyst charging. In addition, compared to the coiled tubing reactor, this pipes-in-series reactor was scalable to larger volumes.

Vieira et al. [40] reported a large-scale cyanation process to the synthesis of Remdesivir (Fig. 5d-e and Table 4f). The investigated step was exothermic and these exotherms could have an adiabatic temperature rise of $4-9{ }^{\circ} \mathrm{C}$, which was easily controlled by the batch cooling as the reactor material was SS. When scaling up the input from $100 \mathrm{~g}$ to $2.75 \mathrm{~kg}$, incomplete conversion of the starting material and much lower diastereoselectivity was obtained. However, the addition of 1.0 M equiv. of TFA solved this problem. The operation
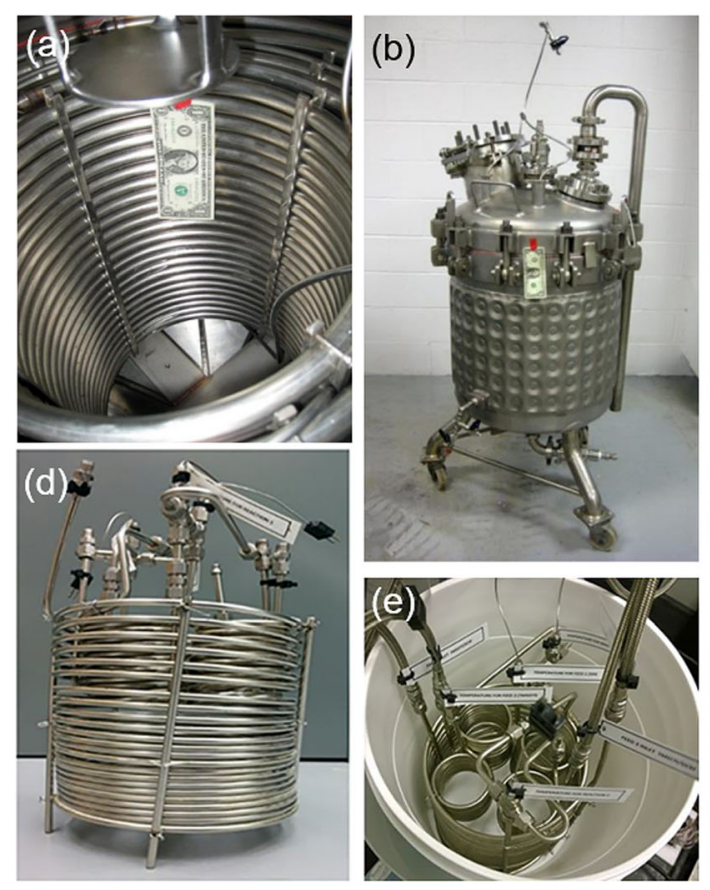

Fig. 5 (a) 32 L SS coiled PFR top view, (b) constant temperature bath to submerge the $32 \mathrm{~L}$ coil, and (c) a bottom of pipes and jumpers for a $360 \mathrm{~L}$ vertical pipes-in-series PFR for two-phase reaction. (Reprinted with permission from Ref. [39]. Copyright 2016 American Chemical Society). Picture of kilo-lab flow chemistry equipment: (d) side view and (e) top view of the SS PFR. (Reprinted with permission from Ref. [40].
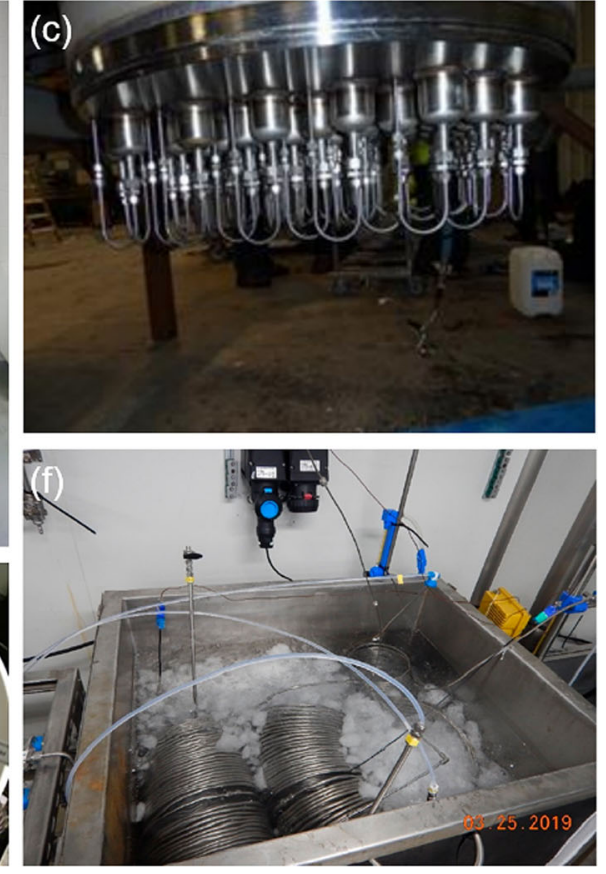

Copyright 2020 American Chemical Society. Further permissions related to the material excerpted should be direct to the ACS. https://pubs.acs. org/doi/10.1021/acs.oprd.0c00172). (f) Picture of a continuous cryogenic reactor submerged in an $\mathrm{EtOH} / \mathrm{CO}_{2}$ batch. (Reprinted with permission from Ref. [41] Copyright 2020 American Chemical Society) 
temperature was $-30{ }^{\circ} \mathrm{C}$ instead of $-40{ }^{\circ} \mathrm{C}$ because TFA has limited solubility in the TMSOTf/DCM mixture, and clogged the line gradually. After applying the optimal conditions, high solution purity and diastereoselectivity were observed.

Cole et al. [41] built an equipment set for the production scale of continuous cryogenic lithium-halogen exchange (Fig. 5f and Table $4 \mathrm{~g}$ ). Briefly, $n$-BuLi and bromide were precooled and mixed in a T-mixer and then entered the $164 \mathrm{~mL}$ SS lithiation reactor, then the solution mixed with precooled imine and entered the $476 \mathrm{~mL} \mathrm{SS}$ addition reactor. The aqueous $\mathrm{HCl}$ in $\mathrm{MeOH}$ stream was precooled and met the process stream first, then entered the 3.19 L PFA chiral auxiliary cleavage reactor. Clogging happened during the 16 days campaign, however, disassembly was not required as the clogging could be resolved by warming the reactor while flow continued.

Table $4 \mathrm{~h}$ shows the scheme of thermal ethoxyethyl deprotection $[25,45]$. Three PFR reactors were designed, and all of them were constructed from $7.75 \mathrm{~mm}$ i.d. Hastelloy. The lengths of these three reactors were 255, 53, and $153 \mathrm{~m}$, with volumes of $12,2.5$, and $7.2 \mathrm{~L}$, respectively. Accordingly, the reaction conditions were different, as de-

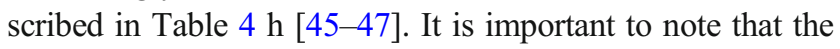
second PFR's coil diameter was smaller $(<10 \mathrm{~cm})$ than the other two, and that it fit inside a $10 \mathrm{~cm}$ inner-diameter $/ 1.2 \mathrm{~m}$ tall steam heating pipe. Therefore, the heat transfer to and from the PFR was better than that of a forced convective oven.
In addition, the smaller diameter of the coil reduced the axial dispersion number $\left(D^{*} / u L=0.001\right.$ in the second reactor $)$, compared to the PFRs with larger coil diameters [36].

There are other publications that report on reactions performed in PFRs [23, 49-63], which are not discussed in detail here.

\section{CSTRs-in-series}

As mentioned above, a CSTR has a broader RTD than a batch reactor or PFR. Integrating more CSTRs (i.e., CSTRs-in-series) could narrow the RTD, but it is usually still broader than a PFR because of the limited reactor numbers. Figure $6 a-b$ provide an example of the RTD measurements of a 5-stage CSTRs-in-series [16]. The designed residence time was $3.5 \mathrm{~h}$ in each stage, however, tracer molecules could spread for approximately $20 \mathrm{~h}$ in the 1 st stage and for more than $40 \mathrm{~h}$ in the 5th stage (Fig. 6a). As more CSTRs were integrated, the RTD narrowed (Fig. 6b). The 5-stage CSTRs-in-series system described in Fig. 6a-b was designed for a reactive-crystallization process, and the yield obtained was $89.6 \%$ in the 5th stage [16]. To further increase the reaction yield, the authors integrated a PFR before the 1st stage CSTR. Figure 6c-d show the RTD measurements for the PFR-CSTRs-in-series system. Slightly narrower RTDs were observed, compared with the 5-stage CSTRs-in-series system, and a $91.3 \%$ yield was
Fig. 6 RTD measurements of (a)(b) the CSTR cascade, and (c)(d) PFR-CSTR cascade system. Solid lines are experimental RTD profiles and dashed lines are RTD profiles based on a CSTRsin-series model. (Reproduced from Ref. [16] with permission from the Royal Society of Chemistry)
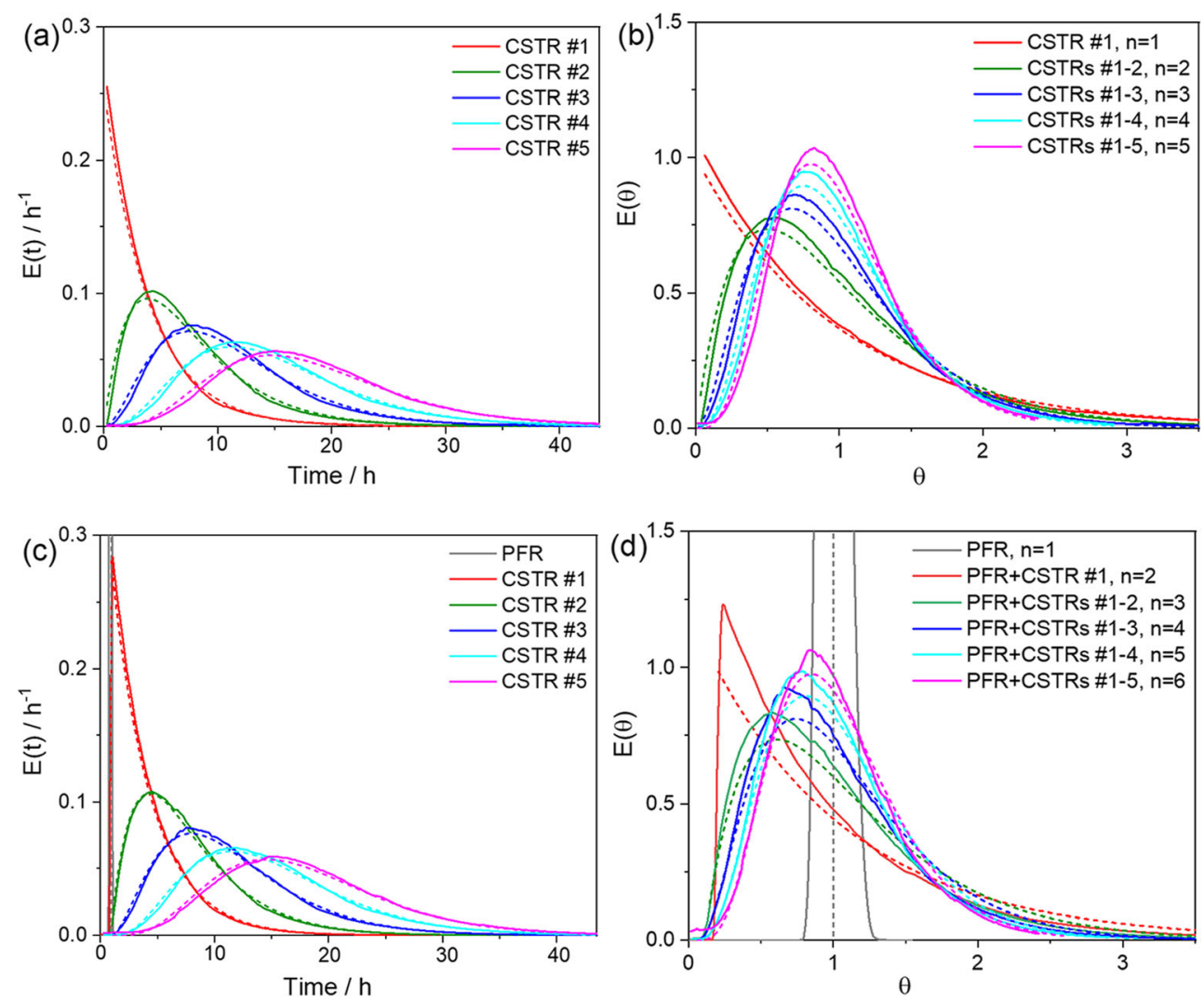
obtained. As well known, there is an induction period (from the start of reaction to crystallization) for reactive crystallization processes. Therefore, it could be economically beneficial to integrate a PFR before the 1st stage CSTR (i.e., PFR was used before the onset of the crystallization).

A CSTR or CSTRs-in-series could be used for liquid, liquid-liquid, and liquid-solid phase reactions. Compared with a PFR, CSTRs-in-series have much higher solid-handling capacity $[64,65]$, and could buffer out the fluctuations of reagent feeds. In a CSTR, we assume the mixture within the reaction is perfectly mixed, and no time or position dependence of the temperature, concentration, or reaction rate inside the reactor at steady state [20]. The volume $(V)$ necessary to achieve conversion $(X)$ is [20],

$V=\frac{F_{A 0} X}{-r_{A}}$

Compared with a PFR, a larger size CSTR is necessary to achieve the same conversion (except zero-order reactions), as the reaction occurs in a CSTR with the lowest reactant concentration. Consider a second-order reactive crystallization with a conversion of $97 \%$ [8], the volume of the corresponding PFR is $1.2 \mathrm{~L}$, and $12.4 \mathrm{~L}$ for a single-stage CSTR. By approximating a PFR with a four-stage CSTRs-in-series, the volume is reduced from $12.4 \mathrm{~L}$ to $2 \mathrm{~L}$ [8].

The Damköhler number, $D a$, which is defined as the ratio of the reaction rate of $\mathrm{A}$ to the convective transport rate of $\mathrm{A}$ at the entrance of the reactor, is often used to estimate the degree of conversion achieved in continuous reactors [20].

$D a=\frac{-r_{A 0} V}{F_{A 0}}$

For a first-order reaction, [20].

$D a=\tau k_{1}$

where $\tau$ is the space time, which can be obtained by dividing the reactor volume by the volumetric flow rate $\left(v_{0}\right)$ entering the reactor,

$\tau=\frac{V}{v_{0}}$

Conversion $X$ of a first-order liquid-phase reaction can be described in terms of $D a,[20]$.

$X=1-\frac{1}{(1+D a)^{n}} \quad($ reactor number $n=1,2,3, \ldots)$

For a single stage reactor, $n=1$, and eq. (36) will simplify to

$X=\frac{D a}{1+D a}$
Therefore, a conversion of greater than $90 \%$ is expected when $D a$ is greater than 10; conversely, a conversion of less than $10 \%$ is obtained when $D a$ is less than 0.1. Based on Fig. 7a-b, the number of CSTRs required to achieve a conversion of $90 \%$ were 1, 6, 13, 25 and 48 for $D a$ of 10, 0.5, 0.2, 0.1 and 0.05 , respectively.

For a second-order reaction, [20].

$D a=\tau k_{2} C_{A 0}$

Accordingly, conversion $X$ of a second-order reaction can be expressed as, [20].

$X=\frac{(1+2 D a)-\sqrt{(1+4 D a)}}{2 D a}$

From Fig. 7c, a $D a$ value of 90 is necessary to achieve a conversion of $90 \%$, while a $D a$ value of 2 achieves $50 \%$ conversion. This means that a 45 -fold increase in $D a$ (this can be attained by increasing either the reaction temperature or the CSTR volume) will increase the conversion less than two times for a single CSTR. Thus, to obtain a relatively high conversion while minimizing reactor volume and reaction temperature, it is necessary to use CSTRs-in-series to approximate a PFR. From eq. (38), we observe that $D a$ decreases as the reactant concentration decreases for a second-order reaction. Therefore, for a 4-stage CSTRs-in-series system, $D a$ decreases stage by stage due to the decreasing concentration of reactants (Fig. 7d). In addition, the conversions for stages $1-4$ are $71.6,87.5,93.0$ and $97.0 \%$, respectively [8]. This translates to conversion changes in each vessel are 71.6, 15.9, 5.5, and $4 \%$, respectively. As the later stages provide less conversion, their addition should be dependent on the balance between simplicity and cost (fewer vessels), and a narrower RTD and higher conversion (more vessels). Typically, the number of stages in CSTRs-in-series is 3-5.

Figure 8 and Table 5 show several examples of reactions carried out in CSTRs-in-series. White et al. [66] investigated a Schotten-Baumann reaction that formed a cytotoxic API using a CSTRs-in-series system (three $12 \mathrm{~L}$ vessels). For this reaction, either a PFR or CSTRs-in-series would work. The reasons the authors selected the CSTRs-in-series are: 1) the evolution of $\mathrm{CO}_{2}$ gas during the reaction would easily partition into the head space of a CSTR, but result in a third phase in a PFR, 2) compared to a PFR, CSTRs could provide the benefit of dampening out some temporary inaccuracies without large fluctuation in the effective stoichiometry, and 3) impurity levels are high when mixing is poor. Figure $8 \mathrm{a}$ and Table $5 \mathrm{a}$ provide the process flow diagram and the scheme, respectively. The three feeds (i.e., 5-Bromothiophene-2-sulfonamide in MeTHF/iPrOAc, 2,4-dichlorobenzoyl chloride in Toluene, $\mathrm{Na}_{2} \mathrm{CO}_{3}$ in water) were pumped into the first CSTR continuously, and the resulting two-phase mixture was then transferred stage to stage, maintaining a constant level. The 
Fig. 7 (a) Conversion as a function of the number of CSTRsin-series for different Damköhler numbers for a first-order reaction, (b) number of CSTRs-in-series required to obtain a conversion great than $90 \%$ or $50 \%$, (c) conversion as a function of the Damköhler number for a secondorder reaction in a single CSTR, and (d) conversion in each stage for a typical second-order reaction. (Fig. 7d is adapt from Ref. [8] with permission from the Royal Society of Chemistry)
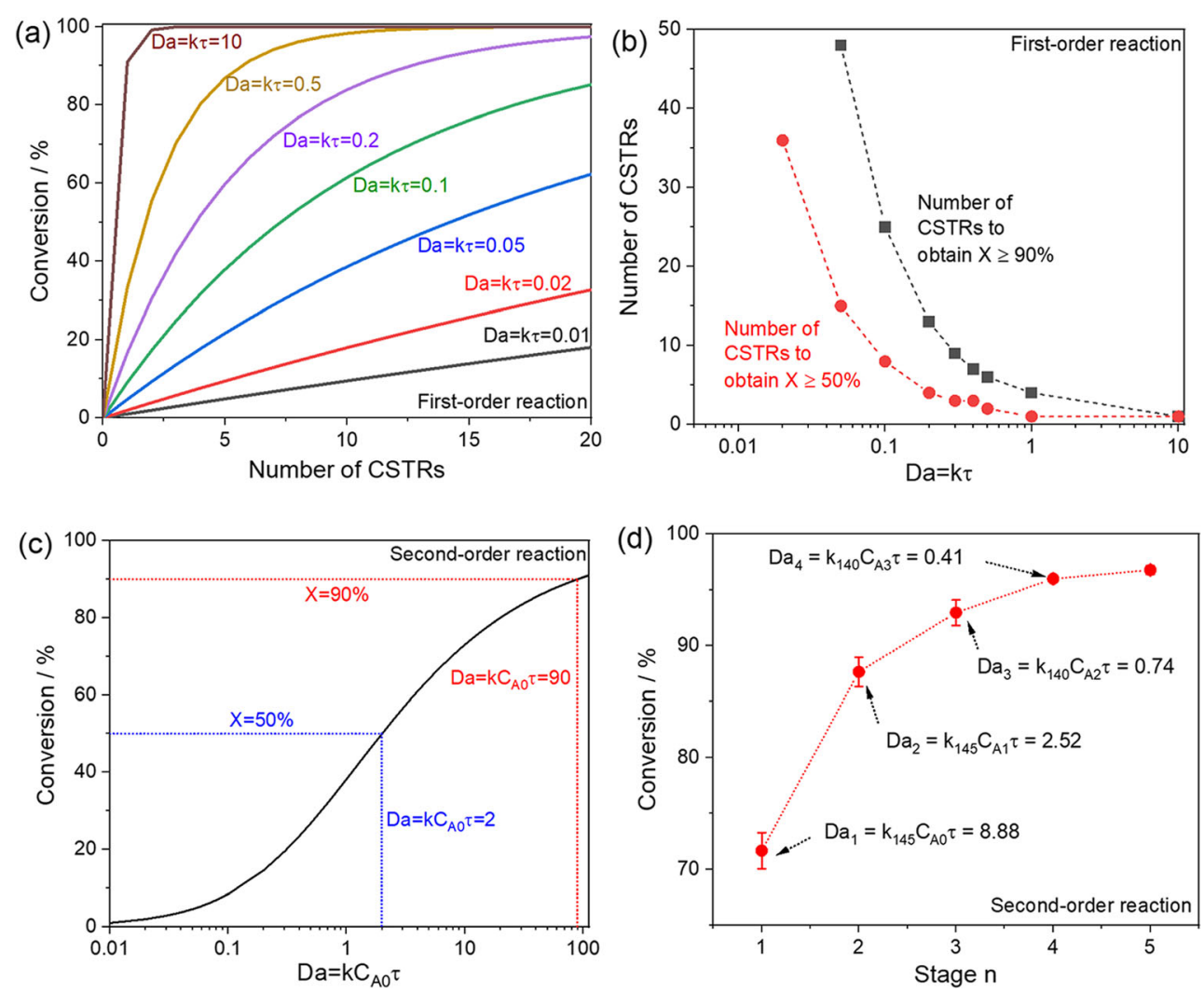

operating temperature was $65^{\circ} \mathrm{C}$, the $\bar{t}$ was $1 \mathrm{~h}$ in each CSTR, and the throughput was $5 \mathrm{~kg} /$ day. As the equipment set was portable, dedicated, and disposable, the potential for crosscontamination was eliminated.

Braden et al. [67] reported a Barbier Grignard formation and coupling, along with quench and neutralization. The authors used three CSTRs-in-series (see Fig. 8b, the third CSTR from the left was not used) to produce $5 \mathrm{~kg}$ /day product in fume hoods. Table $5 \mathrm{~b}$ provides the relevant scheme. The reactors ran $90 \mathrm{~min}$ in the Grignard CSTR, $30 \mathrm{~min}$ in the quench, and $30 \mathrm{~min}$ in the carbonate wash. Compared with the batch process, this continuous process could reduce racemization of the unstable tetrahedral intermediate. This is because the product is not stable from racemization until after the carbonate wash, and the batch process takes longer between the Grignard coupling reaction and the quench reaction, which allowed more time for racemization. In addition, the continuous process is safer because: 1) the Grignard formation reaction has runaway potential in a $100 \mathrm{~L}$ batch reactor (operating in batch mode in a $100 \mathrm{~L}$ vessel provides the same overall throughput as the $2 \mathrm{~L}$ continuous reactors), and 2) much less excess $\mathrm{Mg}$ was required quenching at the end, and less hydrogen gas is generated. The authors selected CSTRs-in-series instead of a PFR because of the solid $\mathrm{Mg}$ reagent, which was sequestered in the CSTR by an internal settling pipe. During the entire $75 \mathrm{~h}$ continuous run, a high enantiomeric excess (ee) was obtained, which averaged $>99 \%$.

$\mathrm{Hu}$ et al. [8, 16] developed an automated multi-stage continuous reactive crystallization system with in-line PATs for a high viscosity process. A solitary PFR was not considered because of the high solid concentration; rather, a hybrid approach was taken. Figure $8 \mathrm{c}$ shows the process flow diagram of the PFR-CSTRs system. The reactive crystallization consists of a second order $\mathrm{C}-\mathrm{N}$ bond-forming reaction between a nitrile species and a secondary amine hydrochloride, in which the resulting API adduct (N,N-dialkyl guanine) precipitates out as a hydrochloride salt (Table $5 \mathrm{c}$ ). The integration of a PFR before the first CSTR increased the yield by $1.7 \%$, as discussed above. In addition, for this highly exothermic reaction, the temperature was observed to be quite stable for the continuous process. This temperature stability could have contributed to lower impurity levels and higher yields. Conversely, the temperature of the corresponding batch process fluctuated over a wide range, as heat was quickly released during a very short time interval.

Duan et al. [68] investigated the flow epoxidation using catalytic methyltrioxorhenium (MTO) and aqueous $\mathrm{H}_{2} \mathrm{O}_{2}$ (Table 5d and Fig. 8d). The authors used a PFR initially, and low conversion was obtained due to the formation of a biphasic layer and insufficient mixing. CSTRs provided better mixing and yielded similar results to those in the batch 


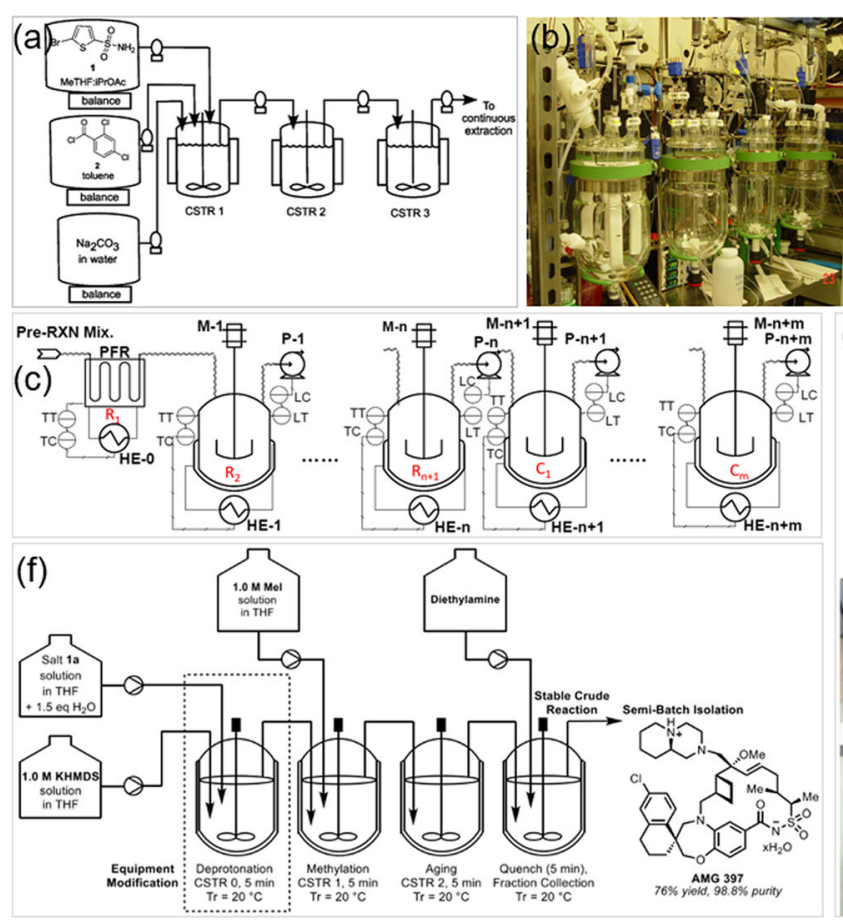

Fig. 8 (a) Process flow diagram of CSTRs-in-series used for SchottenBaumann continuous reaction (Reprinted with permission from Ref. [66]. Copyright 2012 American Chemical Society), (b) 2 L and 1 L CSTRs-inseries used for continuous Barbier Grinard, quench, and neutralization (Reprinted with permission from Ref. [67]. Copyright 2017 American Chemical Society), (c) process flow diagram of a continuous reactive crystallization system (R: reactor; C: crystallizer; TT: temperature transmitter; TC: temperature controller; LT: Level transmitter; LC: level controller; HE: heat exchanger; M: motor; P: pump. Adapt from Ref. [8] with permission from the Royal Society of Chemistry), (d) process flow diagram of the epoxidation reaction using catalytic methyltrioxorhenium

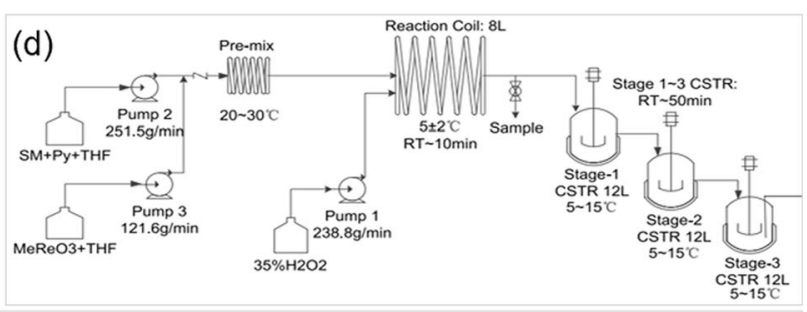

(e)
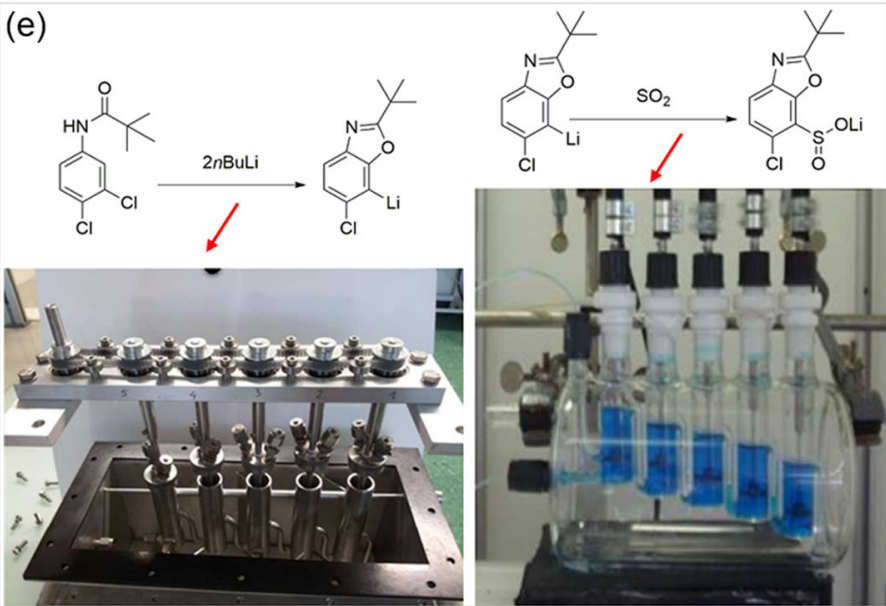

(MTO) and aqueous $\mathrm{H}_{2} \mathrm{O}_{2}$ (Reprinted with permission from Ref. [68]. Copyright 2020 American Chemical Society), (e) the two CSTRs-inseries system used in the synthesis of benzoxazole from N-pivaloyl 3,4dichloro aniline (Reproduced with permission from Ref. [26]. Copyright 2017 American Chemical Society. Further permissions related to the material excerpted should be directed to the ACS. https://pubs.acs.org/ doi/10.1021/acs.oprd.7b00254.), and (f) the continuous flow process of AMG 397, in which the deprotonation, methylation, aging, and quench occur in 4 CSTRs-in-series. $T_{r}$ is the reactor temperature. Reprinted with permission from Ref. [69]. Copyright 2021 American Chemical Society)

highest temperatures after the system stabilized because of the addition of $n$-butyl lithium. For the second reaction step, borosilicate glass was used because SS is not compatible with the high acidity of the reaction medium. Sulfur dioxide was added in the first vessel, causing it to have the highest temperature after the system stabilized. Figure $9 \mathrm{~b}$ shows the simulation results for the heat profiles in each vessel.

Tom et al. [69] developed the methylation of octacycle to AMG 397 (Fig. 8f and Table 5f). Initially a PFR-CSTRs-inseries system was used; however, clogging occurred when the process was operated over a long period because of accumulation of the major by-product KI. A CSTR was used to replace the PFR to ensure the solid transfer during the deprotonation step. Thus 4-CSTRs-in-series was used for deprotonation, methylation, aging, and quench vessel, respectively. A pressure cascade was implemented to transfer the reaction mixture between the $300 \mathrm{~mL}$ CSTRs consistently under an inert atmosphere. The throughput was $30 \mathrm{~g} / \mathrm{h}$ of starting material, and $115 \mathrm{~g}$ was successfully processed over $4 \mathrm{~h}$. More specifically, no precipitation in the first CSTR, no transfer issues, and no clogging were observed. The reaction system 
Table 5 Selected examples of reactions performed in a CSTRs-in-series.

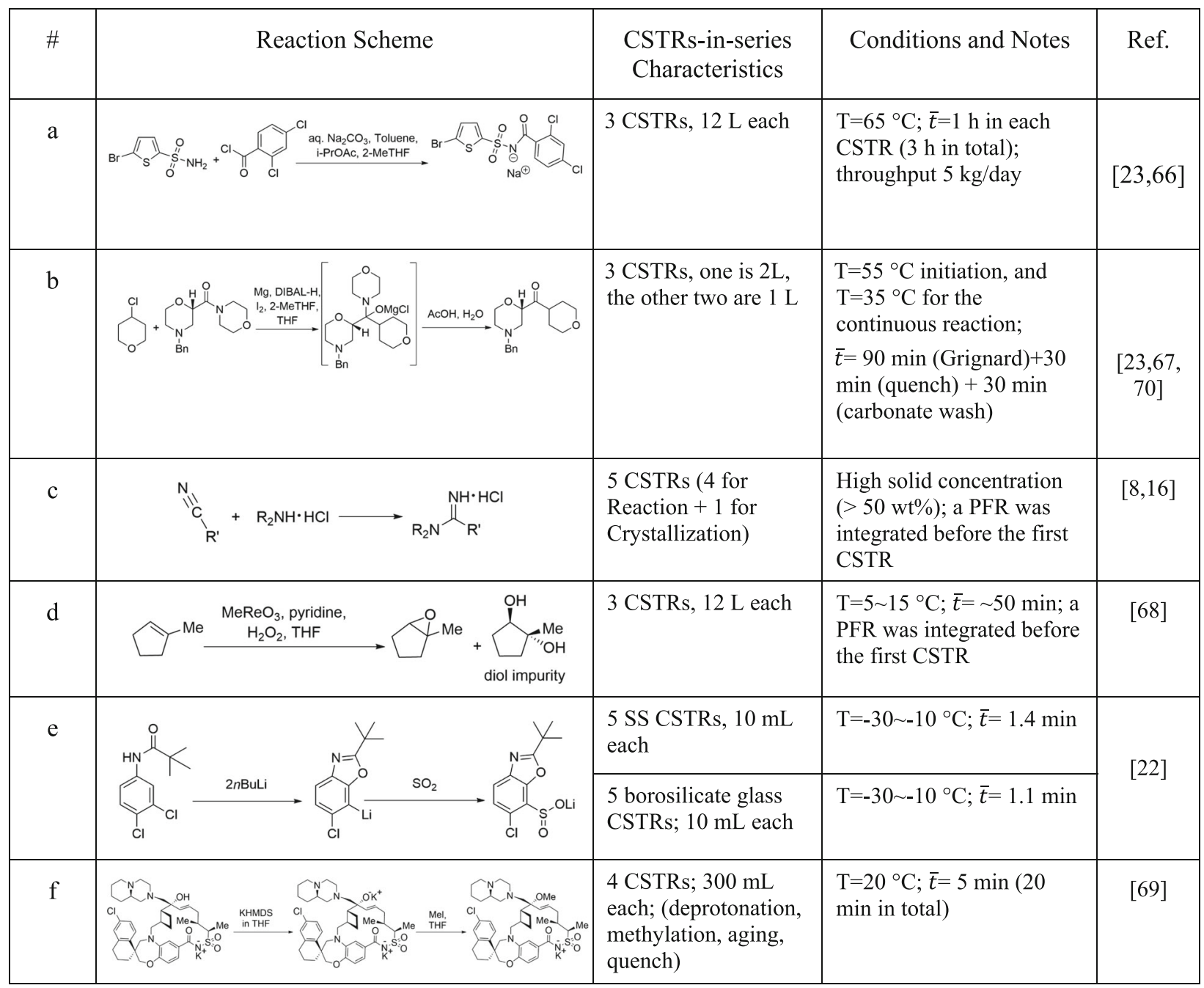

achieved a state of control after approximately two residence times and complete conversion (> 95\% AMG 397) was obtained.

There are other publications that report on reactions performed in CSTRs-in-series [71-77], which are not discussed in detail here.

\section{Selected PATs in continuous reactors}

Process analytical technology (PAT) is defined by the U.S. Food and Drug Administration (FDA) as "a system for designing, analysing, and controlling manufacturing through timely measurements (i.e., during processing) of critical quality and performance attributes of raw and in-process materials and processes, with the goal of ensuring final product quality" [78]. Approximately $70 \%$ of PAT applications are developed for pharmaceutical manufacturing because of regulatory requirements [79]. Batch-produced APIs are analyzed by off- line instruments (e.g., HPLC, GC) to verify their quality attributes; however, in-line/on-line continuous monitoring largely based on PATs is necessary for the continuous manufacturing. These PATs could activate feed-forward and feedback control actions to ensure the quality of the APIs, as well as the drug product. During the reactor design process, it is important to consider the PATs that will be incorporated into the system (e.g., design ports for suitable PATs). Although there are many commonly used PATs [79-90], herein we only briefly discuss the ReactIR and focused beam reflectance measurement (FBRM), which could be used in continuous reactors.

ReactIR is a real-time, in situ mid-infrared based system that enables tracking of soluble reactants, intermediates, products and by-products during the reaction process. This provides useful information about initiation, conversion, intermediates and endpoints of a reaction [8, 16, 91-93]. A ReactIR probe could be located in a batch reactor, a CSTR, or any stage of a CSTRs-in-series, while a ReactIR flow cell can be placed at the exit of a PFR [94]. For example, Wernik et al. [75] used 
Fig. 9 Heat profiles for the startup phase of each vessel for the (a) first reaction step, and (b) second reaction step CSTRs-in-series (Reprinted with permission from Ref. [26]. Copyright 2020 American Chemical Society. Further permissions related to the material excerpted should be directed to the ACS. https://pubs. acs.org/doi/10.1021/acs.oprd. 7b00254)
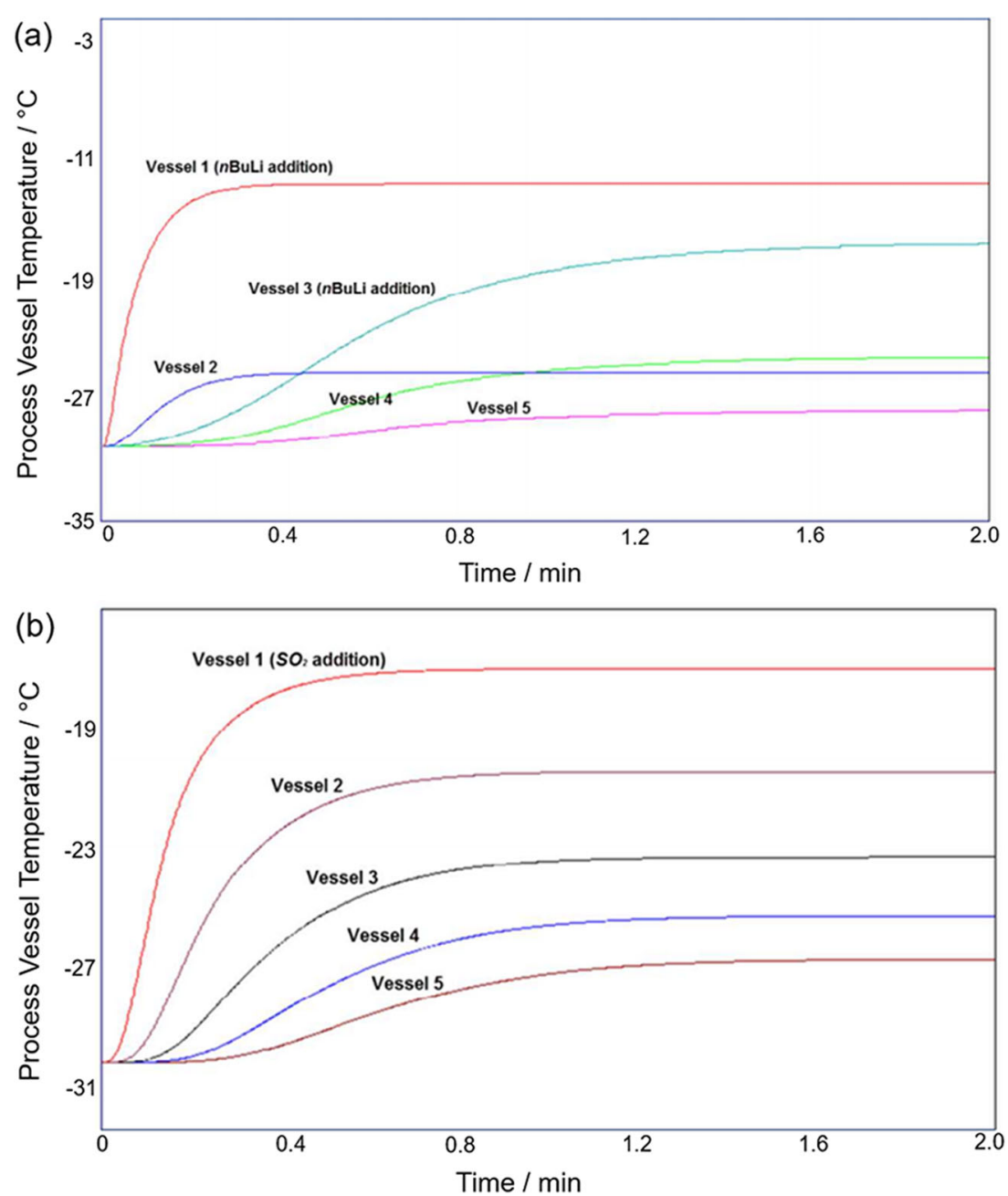

ReactIR in the second CSTR to monitor the formation of diazoketone at $2107 \mathrm{~cm}^{-1}$. The concentration of $\mathrm{CH}_{2} \mathrm{~N}_{2}$ cannot be monitored because the overlap of the characteristic stretch between $\mathrm{CH}_{2} \mathrm{~N}_{2}\left(2097 \mathrm{~cm}^{-1}\right)$ and diazoketone; Hu et al. [8, 16] used ReactIR in the last stage of CSTRs-inseries to monitor the concentration of reactant in the mother liquor; Beaver et al. [74] developed ReactIR method to monitor both the consumption of 2-bromopropene and the generation of product to reduce the safety risk relevant to the accumulation of the Grignard precursor.

FBRM is a probe-based instrument that tracks changing particle size and counts in real-time, and has been widely used in: 1) developing and optimizing crystallization process [95-99], 2) tracking and troubleshooting crystallizer systems [100-105], and 3) even monitoring polymorphic forms $[103,106]$. The FBRM probe could be located in a batch crystallizer, or in CSTRs-in-series systems for reactive crystallization processes [8, 16]. For example, $\mathrm{Hu}$ et al. [8, 16] used FBRM in the last stage of CSTRs-in-series to track changing chord length in real time.

\section{Selected points for attention}

\section{Density change}

Johnson et al. [25] discussed thermal expansion in a PFR. For exothermic or endothermic reactions, the temperature profile along the length of a PFR is not uniform, and this will influence the reaction rate as well as the residence time [25]. When the reaction mixture is heated, it will generally expand, resulting in higher volumetric flow rate. Accordingly, the residence time will decrease, possibly causing incomplete conversion of the reactants (the conversion also depends on the reaction rate change). Conversely, when the reaction mixture is cooled, the residence time will increase, possibly resulting in over-reacted material (if the influence of the reaction rate change is less than that of the residence time change). Thus, it is useful to understand the thermal expansion phenomenon within a reactor, as described in eq. (40) [25, 107].

$$
\left.\frac{\delta V_{r x n \text { mix }}}{\partial T}\right|_{P} \frac{1}{V_{r x n \text { mix }}}=\beta
$$


where $\left.\frac{\delta V_{r x x} \text { mix }}{\partial T}\right|_{P}$ is the volume change of the reaction mixture for different temperatures at constant pressure, $V_{r \times n}$ mix is the volume of the reaction mixture, and $\beta$ is the volumetric thermal expansion coefficient.

In the CSTRs-in-series systems for the described reactive crystallization process $[8,16]$, the precipitation of the product from the reaction mixture could result in the density increase, and accordingly influence the residence time. If the reaction system sensitive to the reaction time, measures should be taken to mitigate this impact.

\section{Clogging and fouling}

Clogging and fouling are issues that need to be considered, as they can lead to process failure. Hu et al. [8] reported a high temperature and high viscosity continuous reactive crystallization system in CSTRs-in-series, and revealed that the transfer tubing between stages easily clogged, restricting continuous pumping of the slurry. A "forward-backward" burst pumping strategy was developed to enable transfer of the high viscosity slurry from one CSTR to the next. More specifically, the transfer tubing inserted into the bottom of the previous vessel, and on the top of the next vessel. In this way, the slurry could only be transferred in the forward direction. The feed pump had a constant flow rate of $3.3 \mathrm{~mL} / \mathrm{min}$, while the transfer pumps ran forward at $150 \mathrm{~mL} / \mathrm{min}$ for $25 \mathrm{~s}$, after which they ran backward at $150 \mathrm{~mL} / \mathrm{min}$ for approximately $15 \mathrm{~min}$. During the latter, the transfer tubing was emptied (i.e., made ready for the next cycle). In a hydroformylation reaction [23] where solids precipitate from the reaction mixture, potentially clogging the reactor tubing, a strategy of "pulsating flow" was used. The flow was forced back and forth by approximately $1 \mathrm{~m}$, preventing solids from accumulating in the tube.
Fouling, or encrustation, is a phenomenon in which solids precipitate and deposit on the internal surfaces of equipment, such as impellers, PAT probes, and the inner walls of vessels. Fouling on the vessel walls will reduce the heat transfer, which could influence the reaction rate, resulting in decreased yield. Many strategies [99, 108-114] have been developed to avoid fouling in continuous crystallization, which can also be used in reactive crystallization processes, including: (1) mechanical devices (e.g., addition of baffles, scrapes, rotating shafts), (2) surface energy or roughness modification via coating (e.g., gold), (3) operating conditions (e.g., mixing, supersaturation level, flow rate, seeding), (4) process dynamics (e.g., use of ultrasonic vibrations, temperature cycling), (5) polymeric excipients (e.g., hydroxylpropyl methylcellulose (HPMC)), (6) model-based strategies, and (7) PAT-based strategies.

\section{Scaling-up}

The ultimate goal of research and development (small scale, typically on the order of $\mathrm{mg}$ to $1 \mathrm{~kg}$ ) is production (large scale, typically on the order of $10 \mathrm{~kg}$ and higher). There are several options for scaling a continuous process from lab to plant $[7,115]$ : 1) running for a longer period of time; 2) scaling-out (numbering up/ parallelization); 3) scaling-up (increasing size). A combination of scaling-out and scaling-up is not uncommon for commercial-scale production, because the middlesized reactor can still benefit from enhanced heat transfer and safety, without any further re-optimization [7]. However, the most common strategy to achieve target throughput is scaling-up. The technical challenges of this approach include the changes of reactor
Fig. 10 Heat transfer between hot reaction mixture, reactor wall and cooling medium

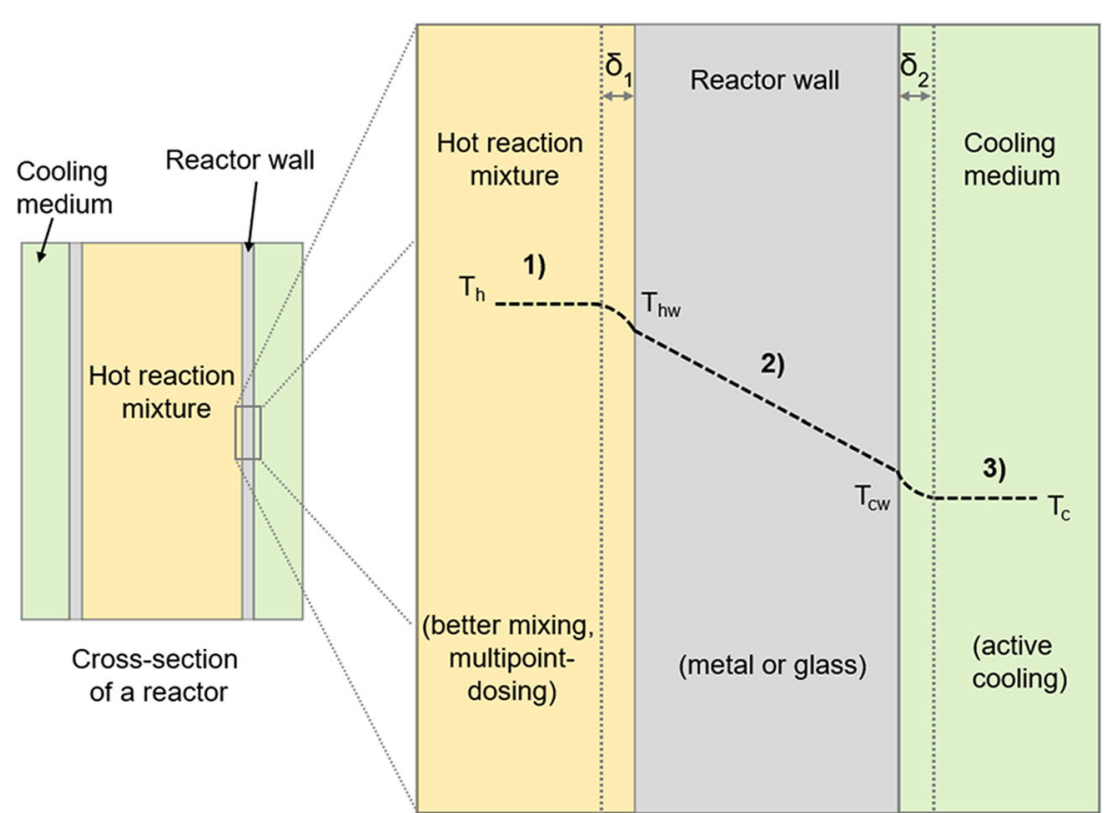


performance (e.g., heat transfer, safety) and reaction outcome (e.g., yield, impurity), which largely caused by reduced specific area of the reactor.

As described by Berton et al. [115], a major concern during the scaling-up process is insufficient heat transfer, especially for fast reaction types such as nitration, organolithium, Grignard and reduction. The limitations of heat transfer within the continuous reactors are (see Fig. 10): 1) transferring heat from reaction medium to inside of reactor wall; 2) transferring heat across the reactor wall; 3) removing the heat from outside of reactor wall. Point 1) is the most challenging problem, which can be mitigated by inducing better mixing inside the reaction zone (e.g., static mixers, packing or porous media, baffled walls, Coriolis flow path) and applying multipoint-dosing strategy as mentioned in Fig. 9a. It is important to notice the space between the dotted line in the hot reaction mixture and the reactor wall (i.e., film thickness $\delta_{1}$ ), where the heat transfer rate is significantly lower than in the reaction mixture. This poor hear transfer is due to the laminar flow that is usually obtained near the wall. Better mixing could reduce film thickness $\delta_{1}$. Point 2) can be addressed by actively pumping the cooling media across the reactor surface instead of being immersed in the cooling media. Increasing the pumping rate could help to reduce film thickness $\delta_{2}$. Point 3) can be addressed simply by minimizing the wall thickness and choosing appropriate materials such as metal and glass.

\section{Conclusions}

In this article, several relevant theories and models (i.e., RTD theory, axial dispersion model, CSTRs-in-series model) are summarized to facilitate effective continuous reactor design and selection. Before the design and selection of continuous reactors can be made, input data such as reaction kinetics, and enthalpy of reaction are required. Several examples in the pharmaceutical industry that use PFRs and CSTRs-in-series are provided. PATs are important tools that provide real-time in-line continuous monitoring of reactions, and should be considered in the reactor design process. There are other points that require special attention, including density change caused by thermal expansion or solid precipitation, clogging/fouling, and scaling-up.

Acknowledgments The author thanks Keith S. Barbato, Bayan Takizawa, Christopher J. Testa, Stephen C. Born, and Salvatore Mascia for their support to this work.

Availability of data and material Not applicable.

Code availability Not applicable.

\section{Declarations}

Conflicts of interest/competing interests Not applicable.

\section{References}

1. Lee SL, O'Connor TF, Yang X, Cruz CN, Chatterjee S, Madurawe RD, Moore CM, Lawrence XY, Woodcock J (2015) Modernizing pharmaceutical manufacturing: from batch to continuous production. J Pharma Innov 10(3):191-199

2. Adamo A, Beingessner RL, Behnam M, Chen J, Jamison TF, Jensen KF, Monbaliu J-CM, Myerson AS, Revalor EM, Snead DR (2016) On-demand continuous-flow production of pharmaceuticals in a compact, reconfigurable system. Science 352(6281):61-67

3. Badman C, Cooney CL, Florence A, Konstantinov K, Krumme M, Mascia S, Nasr M, Trout BL (2019) Why we need continuous pharmaceutical manufacturing and how to make it happen. $\mathrm{J}$ Pharm Sci 108(11):3521-3523

4. May SA (2017) Flow chemistry, continuous processing, and continuous manufacturing: a pharmaceutical perspective. J Flow Chem 7(3-4):137-145

5. Lawrence XY, Kopcha M (2017) The future of pharmaceutical quality and the path to get there. Int J Pharm 528(1-2):354-359

6. Kleinebudde P, Khinast J, Rantanen J (2017) Continuous Manufacturing of Pharmaceuticals, vol 7703

7. Newman SG, Jensen KF (2013) The role of flow in green chemistry and engineering. Green Chem 15(6):1456-1472

8. Hu C, Finkelstein JE, Wu W, Shvedova K, Testa CJ, Born SC, Takizawa B, O'Connor TF, Yang X, Ramanujam S, Mascia S (2018) Development of an automated multi-stage continuous reactive crystallization system with in-line PATs for high viscosity process. React Chem Eng 3(5):658-667

9. Rogers L, Jensen KF (2019) Continuous manufacturing-the Green chemistry promise? Green Chem 21(13):3481-3498

10. Zhang P, Weeranoppanant N, Thomas DA, Tahara K, Stelzer T, Russell MG, O'Mahony M, Myerson AS, Lin H, Kelly LP (2018) Advanced continuous flow platform for on-demand pharmaceutical manufacturing. Chem Eur J 24(11):2776-2784

11. Testa CJ, Hu C, Shvedova K, Wu W, Sayin R, Casati F, Halkude BS, Hermant P, Shen DE, Ramnath A, Su Q, Born SC, Takizawa B, Chattopadhyay S, O'Connor TF, Yang X, Ramanujam S, Mascia S (2020) Design and commercialization of an end-to-end continuous pharmaceutical production process: a pilot plant case study. Org Process Res Dev 24(12):2874-2889. https://doi.org/10. 1021/acs.oprd.0c00383

12. Hu C, Testa CJ, Wu W, Shvedova K, Shen DE, Sayin R, Halkude BS, Casati F, Hermant P, Ramnath A, Born SC, Takizawa B, O'Connor TF, Yang X, Ramanujam S, Mascia S (2020) An automated modular assembly line for drugs in a miniaturized plant. Chem Commun 56(7):1026-1029

13. Mascia S, Heider PL, Zhang H, Lakerveld R, Benyahia B, Barton PI, Braatz RD, Cooney CL, Evans J, Jamison TF (2013) End-toend continuous manufacturing of pharmaceuticals: integrated synthesis, purification, and final dosage formation. Angew Chem Int Ed 52(47):12359-12363

14. Hu C, Testa CJ, Born SC, Wu W, Shvedova K, Sayin R, Halkude BS, Casati F, Ramnath A, Hermant P, Takizawa B, O'Connor TF, Yang X, Ramanujam S, Mascia S (2020) E-factor analysis of a pilot plant for end-to-end integrated continuous manufacturing (ICM) of pharmaceuticals. Green Chem 22(13):4350-4356

15. Shores BT, Sieg PE, Nicosia AT, Hu C, Born SC, Shvedova K, Sayin R, Testa CJ, Wu W, Takizawa B, Ramanujam S, Mascia S 
(2020) Design of a Continuous Solvent Recovery System for endto-end integrated continuous manufacturing (ICM) of pharmaceuticals. Org Process Res Dev 24(10):1996-2003. https://doi.org/10. 1021/acs.oprd.0c00092

16. Hu C, Shores BT, Derech RA, Testa C, Hermant P, Wu W, Shvedova K, Ramnath A, Al Ismaili L, Su Q, Sayin R, Born S, Takizawa B, O'Connor TF, Yang X, Ramanujam S, Mascia S (2020) Continuous reactive crystallization of an API in PFRCSTR Cascade with in-line PATs. React Chem Eng 5(10): 1950-1962. https://doi.org/10.1039/D0RE00216J

17. Lee CK, Khoo HH, Tan RB (2016) Life cyle assessment based environmental performance comparison of batch and continuous processing: a case of 4-D-erythronolactone synthesis. Org Process Res Dev 20(11):1937-1948

18. Jiménez-González C, Poechlauer P, Broxterman QB, Yang B-S, Am Ende D, Baird J, Bertsch C, Hannah RE, Dell'Orco P, Noorman H (2011) Key green engineering research areas for sustainable manufacturing: a perspective from pharmaceutical and fine chemicals manufacturers. Org Process Res Dev 15(4):900911

19. Helal NA, Elnoweam O, Eassa HA, Amer AM, Eltokhy MA, Helal MA, Fayyaz HA, Nounou MI (2019) Integrated continuous manufacturing in pharmaceutical industry: current evolutionary steps toward revolutionary future. Pharmaceutical patent analyst 8(4):139-161

20. Fogler HS (1999) Elements of chemical reaction engineering. 4th edn.

21. Levenspiel O (1999) Chemical reaction engineering. 3rd edn.

22. Burcham CL, Florence AJ, Johnson MD (2018) Continuous manufacturing in pharmaceutical process development and manufacturing. Annual review of chemical and biomolecular engineering 9:253-281

23. Johnson MD, May SA, Calvin JR, Remacle J, Stout JR, Diseroad WD, Zaborenko N, Haeberle BD, Sun W-M, Miller MT (2012) Development and scale-up of a continuous, high-pressure, asymmetric hydrogenation reaction, workup, and isolation. Org Process Res Dev 16(5):1017-1038

24. Johnson MD, May SA, Kopach ME, Groh JM, Braden T, Shankarraman V, Merritt JM (2019) Design and selection of continuous reactors for pharmaceutical manufacturing. Chemical Engineering in the Pharmaceutical Industry: Active Pharmaceutical Ingredients:367-385

25. Johnson MD, May SA, Kopach ME, Groh JMC, White TD, Cole KP, Braden T, Webster LP, Shankarraman V (2020) Continuous reactors for pharmaceutical manufacturing. In: Continuous Pharmaceutical Processing. Springer, pp. 23-50

26. Susanne F, Martin B, Aubry M, Sedelmeier J, Lima F, Sevinc S, Piccioni L, Haber J, Schenkel B, Venturoni F (2017) Matchmaking reactors to chemistry: a continuous manufacturingenabled sequence to a key benzoxazole pharmaceutical intermediate. Org Process Res Dev 21(11):1779-1793

27. Coker AK (2001) Modeling of chemical kinetics and reactor design. Gulf Professional Publishing,

28. Towler G, Sinnott R (2012) Chemical engineering design: principles, practice and economics of plant and process design. Elsevier

29. Cabaniss S, Park D, Slivinsky M, Wagoner J, Dalvie N, Anderson K, Majewska N (2014) Reactors. https://processdesign. mccormick.northwestern.edu/index.php/Reactors

30. Lindeque RM, Woodley JM (2019) Reactor selection for effective continuous biocatalytic production of pharmaceuticals. Catalysts 9(3):262

31. MacMullin R, Weber Jr M (1935) Concept of residence time distribution. AICHE J 31:409

32. Kopach ME, Murray MM, Braden TM, Kobierski ME, Williams OL (2009) Improved synthesis of 1-(azidomethyl)-3, 5-bis- (trifluoromethyl) benzene: development of batch and microflow azide processes. Org Process Res Dev 13(2):152-160

33. May SA, Johnson MD, Braden TM, Calvin JR, Haeberle BD, Jines AR, Miller RD, Plocharczyk EF, Rener GA, Richey RN (2012) Rapid development and scale-up of a 1 H-4-substituted imidazole intermediate enabled by chemistry in continuous plug flow reactors. Org Process Res Dev 16(5):982-1002

34. Levenspiel O (2013) Chemical reactor Omnibook. Oregon state Univresity book store, Inc. Corvallis, OR

35. Leclerc DF, Smith CJ, Toren Jr EC (1987) Axial dispersion in coiled tubular reactors: the effect of curvature at low dean numbers. Anal Chim Acta 194:109-117

36. Johnson M, Kamm RD (1986) Numerical studies of steady flow dispersion at low dean number in a gently curving tube. J Fluid Mech 172:329-345

37. Kovo A (2008) Mathematical modeling and simulation of dispersion in a nonideal plug flow reactor. J Disper Sci Technol 29(8): 1129-1134

38. Hartman RL, McMullen JP, Jensen KF (2011) Deciding whether to go with the flow: evaluating the merits of flow reactors for synthesis. Angew Chem Int Ed 50(33):7502-7519

39. Johnson MD, May SA, Haeberle B, Lambertus GR, Pulley SR, Stout JR (2016) Design and comparison of tubular and pipes-inseries continuous reactors for direct asymmetric reductive amination. Org Process Res Dev 20(7):1305-1320

40. Vieira T, Stevens A, Chtchemelinine A, Gao D, Badalov P, Heumann L (2020) Development of a large-scale Cyanation process using continuous flow chemistry en route to the synthesis of Remdesivir. Org Process Res Dev 24(10):2113-2121

41. Cole KP, Argentine MD, Conder EW, Vaid RK, Feng P, Jia M, Huang P, Liu P, Sun B, Tadayon S (2020) Development and production of an Enantioselective Tetrahydroisoquinoline synthesis enabled by continuous cryogenic Lithium-halogen exchange. Org Process Res Dev 24(10):2043-2054

42. Cole KP, Groh JM, Johnson MD, Burcham CL, Campbell BM, Diseroad WD, Heller MR, Howell JR, Kallman NJ, Koenig TM (2017) Kilogram-scale prexasertib monolactate monohydrate synthesis under continuous-flow CGMP conditions. Science 356(6343):1144-1150

43. Heider PL, Born SC, Basak S, Benyahia B, Lakerveld R, Zhang H, Hogan R, Buchbinder L, Wolfe A, Mascia S (2014) Development of a multi-step synthesis and workup sequence for an integrated, continuous manufacturing process of a pharmaceutical. Org Process Res Dev 18(3):402-409

44. May SA, Johnson MD, Buser JY, Campbell AN, Frank SA, Haeberle BD, Hoffman PC, Lambertus GR, McFarland AD, Moher ED (2016) Development and manufacturing GMP scaleup of a continuous Ir-catalyzed homogeneous reductive amination reaction. Org Process Res Dev 20(11):1870-1898

45. Frederick MO, Calvin JR, Cope RF, LeTourneau ME, Lorenz KT, Johnson MD, Maloney TD, Pu YJ, Miller RD, Cziesla LE (2015) Development of an $\mathrm{NH} 4 \mathrm{Cl}$-catalyzed ethoxy ethyl deprotection in flow for the synthesis of merestinib. Org Process Res Dev 19(10): 1411-1417

46. Cole KP, Reizman BJ, Hess M, Groh JM, Laurila ME, Cope RF, Campbell BM, Forst MB, Burt JL, Maloney TD (2019) Smallvolume continuous manufacturing of merestinib. Part 1. Process development and demonstration. Org Process Res Dev 23(5):858 869

47. Reizman BJ, Cole KP, Hess M, Burt JL, Maloney TD, Johnson MD, Laurila ME, Cope RF, Luciani CV, Buser JY (2019) Smallvolume continuous manufacturing of Merestinib. Part 2. Technology transfer and cGMP manufacturing. Org Process Res Dev 23(5):870-881

48. Green DW, Southard MZ (2019) Perry's chemical engineers' handbook. McGraw-Hill Education 
49. Ingham RJ, Battilocchio C, Fitzpatrick DE, Sliwinski E, Hawkins JM, Ley SV (2015) A systems approach towards an intelligent and self-controlling platform for integrated continuous reaction sequences. Angew Chem 127(1):146-150

50. Tilstam U (2012) A continuous methylation of phenols and N, HHeteroaromatic compounds with dimethyl carbonate. Org Process Res Dev 16(12):1974-1978

51. Lin H, Dai C, Jamison TF, Jensen KF (2017) A rapid total synthesis of ciprofloxacin hydrochloride in continuous flow. Angew Chem 129(30):8996-8999

52. Zhu R, Reddy R, Ding M, Xu M, Deng C, Tadayon S, Li H, Depew K, Lane B (2021) Development and scale-up of a continuous manufacturing process for a hydrazine condensation reaction. Org Process Res Dev. https://doi.org/10.1021/acs.oprd. 0c00424

53. Hughes DL (2020) Applications of flow chemistry in the pharmaceutical industry-highlights of the recent patent literature. Org Process Res Dev 24(10): 1850-1860

54. Li P, Yang S, Zhu R, Sun B, Li Z, Huang P, Buser JY, Miguel Minguez J, Ryan SJ (2020) Continuous flow conditions for high temperature formation of a benzodioxan pharmaceutical intermediate: rapid scaleup for early phase material delivery. Org Process Res Dev 24(10):1938-1947

55. Zhang L, Bo X, Yao H, Mao M, Wan L, Xin Z (2020) Zinccatalyzed alkylation of aromatic amines in continuous flow. Org Process Res Dev 24(10):2078-2084

56. Miranda LSM, de Souza RO, Leão RA, Carneiro PF, Pedraza SF, de Carvalho OV, de Souza SP, Neves RV (2019) Continuous-flow sequential Schotten-Baumann Carbamoylation and acetate hydrolysis in the synthesis of Capecitabine. Org Process Res Dev 23(11):2516-2520

57. Yu M, Strotman NA, Savage SA, Leung S, Ramirez A (2019) A practical and robust multistep continuous process for manufacturing 5-Bromo-N-(tert-butyl) pyridine-3-sulfonamide. Org Process Res Dev 23(9):2088-2095

58. Campbell Brewer A, Hoffman PC, Martinelli JR, Kobierski ME, Mullane N, Robbins D (2019) Development and scale-up of a continuous aerobic oxidative Chan-lam coupling. Org Process Res Dev 23(8):1484-1498

59. Yu Z, Lu G, Chen J, Xie S, Su W (2018) Conversion of 2, 4difluoroaniline to 1, 3-difluorobenzene using a continuous-flow reactor. J Flow Chem 8(2):51-57

60. McMullen JP, Marton CH, Sherry BD, Spencer G, Kukura J, Eyke NS (2018) Development and scale-up of a continuous reaction for production of an active pharmaceutical ingredient intermediate. Org Process Res Dev 22(9):1208-1213

61. Yu Z, Ye X, Xu Q, Xie X, Dong H, Su W (2017) A fully continuous-flow process for the synthesis of p-cresol: impurity analysis and process optimization. Org Process Res Dev 21(10): 1644-1652

62. Gage JR, Guo X, Tao J, Zheng C (2012) High output continuous nitration. Org Process Res Dev 16(5):930-933

63. Rehbein M, Wolters J, Kunick C, Scholl S (2019) Continuous high-pressure operation of a pharmaceutically relevant Krapcho dealkoxycarbonylation reaction. J Flow Chem 9(2):123-131

64. Pomberger A, Mo Y, Nandiwale KY, Schultz VL, Duvadie R, Robinson RI, Altinoglu EI, Jensen KF (2019) A continuous stirred-tank reactor (CSTR) Cascade for handling solidcontaining photochemical reactions. Org Process Res Dev 23(12):2699-2706

65. Mo Y, Jensen KF (2016) A miniature CSTR cascade for continuous flow of reactions containing solids. React Chem Eng 1(5): 501-507

66. White TD, Berglund KD, Groh JM, Johnson MD, Miller RD, Yates MH (2012) Development of a continuous Schotten-
Baumann route to an acyl sulfonamide. Org Process Res Dev 16(5):939-957

67. Braden TM, Johnson MD, Kopach ME, McClary Groh J, Spencer RD, Lewis J, Heller MR, Schafer JP, Adler JJ (2017) Development of a commercial flow Barbier process for a pharmaceutical intermediate. Org Process Res Dev 21(3):317-326

68. Duan S, Feng X, Gonzalez M, Bader S, Hayward C, Ljubicic T, Lu J, Mustakis J, Maloney M, Rainville J (2020) Developing a multistep continuous manufacturing process for (1 R, $2 \mathrm{R})-2$ Amino-1-methylcyclopentan-1-ol. Org Process Res Dev 24(11): 2734-2744

69. Tom JK, Achmatowicz MM, Beaver MG, Colyer J, Ericson A, Hwang T-L, Jiao N, Langille NF, Liu M, Lovette MA, Sangodkar RP, Kumar SS, Spada S, Perera D, Sheeran J, Campbell K, Doherty T, Ford DD, Fang Y-Q, Rossi E, Santoni G, Cui S, Walker SD (2021) Implementing continuous manufacturing for the final methylation step in the AMG 397 process to deliver key quality attributes. Org Process Res Dev. https://doi.org/10. 1021/acs.oprd.0c00440

70. Kopach ME, Roberts DJ, Johnson MD, Groh JM, Adler JJ, Schafer JP, Kobierski ME, Trankle WG (2012) The continuous flow Barbier reaction: an improved environmental alternative to the Grignard reaction? Green Chem 14(5):1524-1536

71. Içten E, Maloney AJ, Beaver MG, Shen DE, Zhu X, Graham LR, Robinson JA, Huggins S, Allian A, Hart R (2020) A virtual Plant for Integrated Continuous Manufacturing of a Carfilzomib drug substance intermediate, part 1: CDI-promoted amide bond formation. Org Process Res Dev 24(10):1861-1875

72. Içten E, Maloney AJ, Beaver MG, Zhu X, Shen DE, Robinson JA, Parsons AT, Allian A, Huggins S, Hart R (2020) A virtual Plant for Integrated Continuous Manufacturing of a Carfilzomib drug substance intermediate, part 2: Enone synthesis via a Barbier-type Grignard process. Org Process Res Dev 24(10):1876-1890

73. Maloney AJ, Ei I, Capellades G, Beaver MG, Zhu X, Graham LR, Brown DB, Griffin DJ, Sangodkar R, Allian A (2020) A virtual Plant for Integrated Continuous Manufacturing of a Carfilzomib drug substance intermediate, part 3: manganese-catalyzed asymmetric Epoxidation, crystallization, and filtration. Org Process Res Dev 24(10):1891-1908

74. Beaver MG, Shi X, Riedel J, Patel P, Zeng A, Corbett MT, Robinson JA, Parsons AT, Cui S, Baucom K (2020) Continuous process improvement in the manufacture of Carfilzomib, part 2: an improved process for synthesis of the Epoxyketone warhead. Org Process Res Dev 24(4):490-499

75. Wernik M, Poechlauer P, Schmoelzer C, Dallinger D, Kappe CO (2019) Design and optimization of a continuous stirred tank reactor Cascade for membrane-based diazomethane production: synthesis of $\alpha$-Chloroketones. Org Process Res Dev 23(7):13591368

76. Kopach ME, Cole KP, Pollock PM, Johnson MD, Braden TM, Webster LP, McClary Groh J, McFarland AD, Schafer JP, Adler JJ (2016) Flow Grignard and lithiation: screening tools and development of continuous processes for a benzyl alcohol starting material. Org Process Res Dev 20(9):15811592

77. Yadav MB, Kulkarni S, Joshi RA, Kulkarni AA (2016) Continuous flow Doebner-Miller reaction and isolation using continuous stirred tank reactors. Org Process Res Dev 20(9): $1621-1625$

78. FDA (2004) Food and Drug Administration (2004) Guidance for industry: PAT - a framework for innovative pharmaceutical development, manufacturing and quality assurance

79. Pomerantsev AL, Rodionova OY (2012) Process analytical technology: a critical view of the chemometricians. J Chemom 26(6): 299-310 
80. Simon LL, Pataki H, Gr M, Meemken F, Hungerbühler K, Baiker A, Tummala S, Glennon B, Kuentz M, Steele G (2015) Assessment of recent process analytical technology (PAT) trends: a multiauthor review. Org Process Res Dev 19(1):3-62

81. Chanda A, Daly AM, Foley DA, LaPack MA, Mukherjee S, Orr JD, Reid III GL, Thompson DR, Ward HW (2015) Industry perspectives on process analytical technology: tools and applications in API development. Org Process Res Dev 19(1):63-83

82. Bordawekar S, Chanda A, Daly AM, Garrett AW, Higgins JP, LaPack MA, Maloney TD, Morgado J, Mukherjee S, Orr JD (2015) Industry perspectives on process analytical technology: tools and applications in API manufacturing. Org Process Res Dev 19(9):1174-1185

83. Lawrence XY, Lionberger RA, Raw AS, D'costa R, Wu H, Hussain AS (2004) Applications of process analytical technology to crystallization processes. Adv Drug Deliv Rev 56(3):349-369

84. Sistare F, St. Pierre Berry L, Mojica CA (2005) Process analytical technology: an investment in process knowledge. Org Process Res Dev 9(3):332-336

85. Munson J, Freeman Stanfield C, Gujral B (2006) A review of process analytical technology (PAT) in the US pharmaceutical industry. Curr Pharm Anal 2(4):405-414

86. Kourti T (2006) The process analytical technology initiative and multivariate process analysis, monitoring and control. Anal Bioanal Chem 384(5): 1043-1048

87. De Beer T, Vercruysse $\mathrm{P}$, Burggraeve A, Quinten T, Ouyang J, Zhang X, Vervaet C, Remon JP, Baeyens W (2009) In-line and real-time process monitoring of a freeze drying process using Raman and NIR spectroscopy as complementary process analytical technology (PAT) tools. J Pharm Sci 98(9):3430-3446

88. Wu H, Dong Z, Li H, Khan M (2015) An integrated process analytical technology (PAT) approach for pharmaceutical crystallization process understanding to ensure product quality and safety: FDA scientist's perspective. Org Process Res Dev 19(1):89101

89. Fonteyne M, Vercruysse J, De Leersnyder F, Van Snick B, Vervaet C, Remon JP, De Beer T (2015) Process analytical technology for continuous manufacturing of solid-dosage forms. TrAC Trends Anal Chem 67:159-166

90. Vargas JM, Nielsen S, Cárdenas V, Gonzalez A, Aymat EY, Almodovar E, Classe G, Colón Y, Sanchez E, Romañach RJ (2018) Process analytical technology in continuous manufacturing of a commercial pharmaceutical product. Int J Pharm 538(1-2): $167-178$

91. Stead D, Carbone G, O'Brien P, Campos KR, Coldham I, Sanderson A (2010) Asymmetric deprotonation of N-Boc piperidine: react IR monitoring and mechanistic aspects. J Am Chem Soc 132(21):7260-7261

92. Barker G, McGrath JL, Klapars A, Stead D, Zhou G, Campos KR, O'Brien P (2011) Enantioselective, palladium-catalyzed $\alpha$ arylation of N-Boc pyrrolidine: in situ react IR spectroscopic monitoring, scope, and synthetic applications. The Journal of organic chemistry 76(15):5936-5953

93. Foley DA, Doecke CW, Buser JY, Merritt JM, Murphy L, Kissane M, Collins SG, Maguire AR, Kaerner A (2011) ReactNMR and ReactIR as reaction monitoring and mechanistic elucidation tools: the NCS mediated cascade reaction of $\alpha$-thioamides to $\alpha$-thio- $\beta$ chloroacrylamides. The Journal of Organic Chemistry 76(23): 9630-9640

94. Carter CF, Lange H, Ley SV, Baxendale IR, Wittkamp B, Goode JG, Gaunt NL (2010) ReactIR flow cell: a new analytical tool for continuous flow chemical processing. Org Process Res Dev 14(2): 393-404
95. Jiang M, Zhu X, Molaro MC, Rasche ML, Zhang H, Chadwick K, Raimondo DM, Kim K-KK, Zhou L, Zhu Z (2014) Modification of crystal shape through deep temperature cycling. Ind Eng Chem Res 53(13):5325-5336

96. Saleemi A, Rielly C, Nagy Z (2012) Monitoring of the combined cooling and antisolvent crystallisation of mixtures of aminobenzoic acid isomers using ATR-UV/Vis spectroscopy and FBRM. Chem Eng Sci 77:122-129

97. Saleemi AN, Rielly CD, Nagy ZK (2012) Comparative investigation of supersaturation and automated direct nucleation control of crystal size distributions using ATR-UV/ Vis spectroscopy and FBRM. Cryst Growth Des 12(4): 1792-1807

98. Doki N, Seki H, Takano K, Asatani H, Yokota M, Kubota N (2004) Process control of seeded batch cooling crystallization of the metastable $\alpha$-form glycine using an in-situ ATR-FTIR spectrometer and an in-situ FBRM particle counter. Cryst Growth Des 4(5):949-953

99. Worlitschek J, Mazzotti M (2004) Model-based optimization of particle size distribution in batch-cooling crystallization of paracetamol. Cryst Growth Des 4(5):891-903

100. Yu ZQ, Chow PS, Tan RB (2006) Application of attenuated Total reflectance- Fourier transform infrared (ATR-FTIR) technique in the monitoring and control of anti-solvent crystallization. Ind Eng Chem Res 45(1):438-444

101. Wang Z, Wang J, Dang L (2006) Nucleation, growth, and solvated behavior of erythromycin as monitored in situ by using FBRM and PVM. Org Process Res Dev 10(3):450-456

102. Wang XJ, Ching CB (2006) A systematic approach for preferential crystallization of 4-hydroxy-2-pyrrolidone: thermodynamics, kinetics, optimal operation and in-situ monitoring aspects. Chem Eng Sci 61(8):2406-2417

103. O'Sullivan B, Glennon B (2005) Application of in situ FBRM and ATR-FTIR to the monitoring of the polymorphic transformation of D-mannitol. Org Process Res Dev 9(6):884-889

104. Deneau E, Steele G (2005) An in-line study of oiling out and crystallization. Org Process Res Dev 9(6):943-950

105. Barrett P, Glennon B (2002) Characterizing the metastable zone width and solubility curve using Lasentec FBRM and PVM. Chem Eng Res Des 80(7):799-805

106. Schöll J, Bonalumi D, Vicum L, Mazzotti M, Müller M (2006) In situ monitoring and modeling of the solvent-mediated polymorphic transformation of L-glutamic acid. Cryst Growth Des 6(4): 881-891

107. Bridgman PW (1914) A complete collection of thermodynamic formulas. Phys Rev 3(4):273

108. Tachtatzis C, Sheridan R, Michie C, Atkinson RC, Cleary A, Dziewierz J, Andonovic I, Briggs NE, Florence AJ, Sefcik J (2015) Image-based monitoring for early detection of fouling in crystallisation processes. Chem Eng Sci 133:82-90

109. Acevedo D, Yang X, Liu Y, O'Connor TF, Koswara A, Nagy ZK, Madurawe R, Cruz CN (2019) Encrustation in continuous pharmaceutical crystallization process-a review. Org Process Res Dev 23(6):1134-1142

110. Wong SY, Chen J, Forte LE, Myerson AS (2013) Compact crystallization, filtration, and drying for the production of active pharmaceutical ingredients. Org Process Res Dev 17(4):684-692

111. Powell KA, Saleemi AN, Rielly CD, Nagy ZK (2016) Monitoring continuous crystallization of paracetamol in the presence of an additive using an integrated PAT array and multivariate methods. Org Process Res Dev 20(3):626-636

112. Koswara A, Nagy ZK (2015) Anti-fouling control of plug-flow crystallization via heating and cooling cycle. IFAC-PapersOnLine 48(8):193-198 
113. Su Q, Rielly CD, Powell KA, Nagy ZK (2017) Mathematical modelling and experimental validation of a novel periodic flow crystallization using MSMPR crystallizers. AICHE J 63(4):13131327

114. Yazdanpanah N, Testa CJ, Perala SR, Jensen KD, Braatz RD, Myerson AS, Trout BL (2017) Continuous heterogeneous crystallization on excipient surfaces. Cryst Growth Des 17(6):33213330

115. Berton M, de Souza JM, Abdiaj I, McQuade DT, Snead DR (2020) Scaling continuous API synthesis from milligram to kilogram: extending the enabling benefits of micro to the plant. J Flow Chem:1-20

Publisher's note Springer Nature remains neutral with regard to jurisdictional claims in published maps and institutional affiliations.

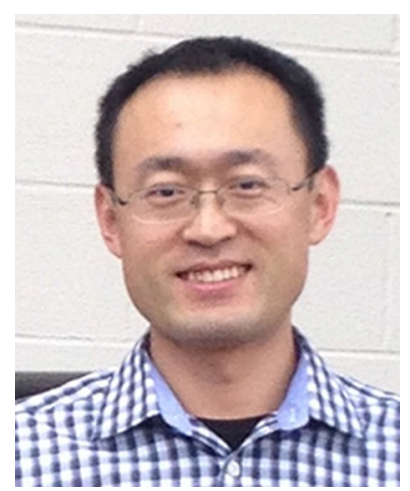

Chuntian Hu received his Ph.D. in the Department of Chemical and Biological Engineering from the University of Alabama in 2015, then entered NYU Tandon School of Engineering as a postdoctoral associate until 2016. He received his BS in Chemical Engineering and Technology from Shandong University of Technology and his MS in Chemical Technology from China University of Petroleum (Beijing). He is currently the Reaction Engineering Director at CONTINUUS Pharmaceuticals (Woburn, MA). His research focuses on end-to-end continuous manufacturing of pharmaceuticals. 